\title{
Social media dynamics of National Sports Federations
}

\author{
Hitesh Mangtani*, Antriksh Jaiswal ${ }^{* *}$ \\ ${ }^{*}$ Independent Researcher (Sports) \& Sports Blogger (Freelance), MBA - Sports Management \\ ** Founder at SportsWe \& Former Senior Digital Strategist - ITW Consulting Pvt. Ltd., MBA - Sports Management. \\ DOI: 10.29322/IJSRP.11.06.2021.p11413 \\ http://dx.doi.org/10.29322/IJSRP.11.06.2021.p11413
}

\begin{abstract}
In order to claim the top spot in the business aspects of Sports, advertising has become the need of the hour. Social media platforms like Twitter, Facebook, Instagram, YouTube and many more have capitalized on the fact of this 'need of the hour' concept allowing governing bodies of sports and National Sports Federations (NSFs) to generate a significant amount of revenue by having a considerable base of fans, followers, enthusiasts and viewers - also termed as 'digital eye-balls' in the world of broadcasting and media promotions. Considering these critical elements (especially the People and Promotional aspects), we are discussing and evaluating the overall growth of the number of followers in various segmented and relatively targeted regions, communities and psychographic locations of Australia, New Zealand, India and the United State of America.
\end{abstract}

Index Terms- Sports, ISFs, NSFs, Social Media, Digitization.

\section{INTRODUCTION}

In this digital era, the influential facet is being visible via multiple channels, be it traditional newspapers headlines or social media platforms. At present, sports is a matter of deep interest, especially for the younger generations. Sports, since time immemorial, has had a great impact on human lives directly or indirectly irrespective of nationalities, religion, colour, creed and sex. Sports is known to be a universal driver of oneness. It is one of the most unifying factors for the millennials and iGen/Gen $\mathrm{Z}$ groups. Everyone wants to stay updated about Sports and the content consumption stands right at the top along with other genres. Evidently things happen regularly and at a sheer rapid pace. It becomes imperative for everyone in this 'staying up-to-date era' to be aware of all events, news and whatever is happening or potentially what is trending according to the 'social buzz'. Social media gives people updates from the world of sports in a precise manner. Precision and being concise has become integral due to the lower attention span of young people.

It leads us to accept the huge digital transformation taking place via different types of content consumption on social platforms. This research focuses particularly on social media platforms in the current circumstances. In sports, there is a lot happening in the background with respect to sports administration, development and overall management in terms of how sports news or information or sports content in the digital world is propagated to the masses. The ocean of social media needs an immense amount of focus along with a lot of energy, time and relentlessness to analyze and put forth content. This can be defined by the means of the $5 \mathrm{Ws}-1 \mathrm{H}$ of the marketing concept:

- How the content is being consumed?

- Why convey 'this' information via 'that' social platform?

- When is it being consumed (the timeline)?

- Where is it being consumed the most (the location)?

- What variety of subject is being preferred/consumed?

- Which is the most preferred platform? or, which is the most effective one, from a business point-of-view? and so on.

These relevant questions will further help NSFs or Sports Governing Bodies to determine the basic principle in order to extensively develop effective and efficient marketing as well as promotion strategies via content creation on social platforms and new media keeping the 5P's, i.e., Product, Price, Promotion, Place and People ${ }^{(l)}$ as the focal point of all decisions in terms of market segmentation, competitor analysis, etc.

\section{THE IDEA}

Sports acts as a magnet to attract and influence people across countries. For International Sports Federations (ISFs) ${ }^{(2)(3)}$, National Sports Federations (NSFs), Ministries, or Governing Bodies and Administrators social media has become one of the most powerful mediums to reach out to people and engage with them. This facilitates the sharing of information in different languages keeping all the written and unwritten rules to be strictly applied and monitored, resulting in greater quality content. With the advent and the insertion of social-networking platforms such as Twitter, Facebook, Instagram, and YouTube (predominantly), the irresistible power of Sports, 
as a medium of communication ${ }^{(4)}$ has increased significantly. Now, one of the parameters for the growth of sports organization is related to the number of followers, enthusiasts ${ }^{(5)}$ and subscribers they have on their social media channels. Through this dynamic social-media examination of major Sports Governing Bodies, or NSFs of the following countries, i.e., Australia (6), India (7), New Zealand ${ }^{(8)}$, and USA ${ }^{(9)}$, this research makes an effort to understand the louds and softs of how the respective NSFs work towards leveraging the true potential of the social media platforms to ensure maximum impact not just within their national sports ecosystem and the community level awareness for effective grassroots development ${ }^{(10)}$ but also act as a template for other sports administrative bodies to try and replicate a similar process of creating a reputation across societies and countries while respecting all cultural norms, to justify and further enhance the reliability of the organization.

There is a massive exploration being carried out in the background not only by the International Sports Federations ${ }^{(11)}$ but also by many of the third-party Sports Consulting \& Media Management agencies, to study, evaluate, analyze and further scrutinize the depth of presence and significant impact of social media (specific to Sports) on the locals in a number of regimes, cultures and the emotional dynamics of our societies in different parts of the world. These emotional dynamics in different regions allow the sporting discipline(s) to be present on social media in a very distinctive manner based on localities, cultural norms, beliefs and to some extent the amount of exposure i.e., the sport, has or wishes to have in the near future. Hence, brand strategists, communication experts \& management professionals are engaged to ensure effective implementation for greater interaction and engagement keeping the sentiments and values alive.

\section{OUR FINDINGS}

In a webinar organized by GSIC about, Embracing the Multisport through Technology and Innovation on $26^{\text {th }}$ August 2020 , with a panel discussion featuring Jonny Cowan, ITTF - Data \& Digital Specialist, Darren Birch, AFL General Manager (Growth, Digital and Audience), Owen Leed, BWF - Commercial \& Communications Director, interesting discussions were ignited about sports content distribution, consumption \& variability on different social platforms predominantly Twitter, Facebook, Instagram and YouTube (12). BWF garnered $735 \mathrm{Mn}$ fans globally and there was a substantial increase in media value of \$627 Mn in 2019. This actually earned BWF the $1^{\text {st }}$ spot in terms of 'highest true reach on Instagram and $2^{\text {nd }}$ spot in terms of 'most likes on Facebook', as per BCW Social

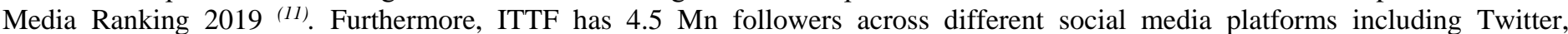
Facebook, Instagram and YouTube. Overall, they have 563+ Mn fans worldwide ${ }^{(12)}$ which earns them $1^{\text {st }}$ spot in terms of 'most comments on Facebook' and $3^{\text {rd }}$ spot in terms of 'most shares on Facebook' as per BCW Social Media Ranking $2019{ }^{(11)}$.

If one considers oneself an exceptional planner and is meticulous about tiny aspects of management, one will agree with the fact that things can go wrong very fast if we do not maintain discipline in what we are doing and how we are going to achieve a goal. Therefore, social media coupled with all the digital strategies in many cases has been (and will continue to be) weaponized (13) in different capacities. Continuing to focus on the 'other' side of the coin, social media platforms can also be held accountable for quote "exploiting various community biases and weaknesses and abetted the growth of conspiracy-touting hate groups and outrage machines" particularly Facebook ${ }^{(14)}$, which now owns Instagram, WhatsApp, Oculus, etc. ${ }^{(15)(16)}$. One of the major reasons (which we can think of) that can be cited here is the United Nations Sustainability Development Goals ${ }^{(17)}$, which is continuously striving to act as a link between Sports being cultivated as a tool for sustainable development in order to tap its full potential ${ }^{(18)}$. In order to do that ISF's, NSF's, respective governing bodies (sports) are trying to utilize and coming up with different digital strategies for information sharing platforms like Twitter, Facebook, Instagram, YouTube to spread awareness and eventually gain recognition in the Global Sports Ecosystem.

Following a similar process ${ }^{(11)}$, this research looked at National Sports Federation's (NSF's) and further shortlisted 69 recognized Australian NSF's ${ }^{(6)}, 33$ recognized Indian NSF's ${ }^{(7)}, 37$ recognized New Zealand NSF's ${ }^{(8)}$ and lastly 60 recognized USA NSF's (9) which have at least three social media accounts fully operations (restricted to Twitter, Facebook, Instagram, YouTube), to further analyze the vogue in the Global Sports Ecosystem. The most powerful tools in simple terms we as a community have is to listen, learn and build empathy which in many ways is responsible for building the schema of human minds and hearts to work together in unison

${ }^{(19)}$. Instead of using social media platforms to manipulate, exploit and further segment the harmful distribution of information to specifically targeted communities, we (the Sports Administrators, Managers and Organizers) should be looking at creating an ecosystem of democracy, by using 'sports' as a language of communication, mode of sharing ideas and most of all to have the opportunity to be heard, voice opinions and be respected ${ }^{(19)}$ as a substitute to being racist in our thoughts and action.

In fact, to some extent we can gauge the communication pattern of the sports organizations (NSFs in this case) by the way social media platform are listed on their respective websites (as in the sequence, i.e., which social media platform is mentioned first and last), where are they located on the website, how are they located and described. In many different ways, the location and actual presence of these social media platforms on websites can reveal how dedicated are the sports organization, NSFs in this case, towards promoting sports and eventually staying connected with the fans, followers, and enthusiasts ${ }^{(5)}$. For instance, Netball New Zealand has Facebook, Twitter, Instagram and YouTube as their line-up visible on the website ${ }^{(20)}$ which reflects their digital visibility via respective platforms, i.e., 70.9k, 16k, 21.7k, 4.68k followers (as of $2^{\text {nd }}$ Feb 2021). We also witnessed a sudden rise in YouTube subscribers for

This publication is licensed under Creative Commons Attribution CC BY.

http://dx.doi.org/10.29322/IJSRP.11.06.2021.p11413

wWw.ijsrp.org 
Sports Climbing Australia ${ }^{(21)}$ (Figure. 61), and we further linked it to the announcement by International Olympic Committee, where breakdancing, surfing, skateboarding and sports climbing have been inducted as Olympic sports for 2024 Paris Olympic Games ${ }^{(22)}$.

In this dynamic and evolving era, it is about solving the problem of changing the nature of content consumption which is drastically shifting to Digital, and with TV ratings declining brands are keen on knowing the full and most important, the real value they are generating with sports sponsorship activities around the world ${ }^{(23)}$. In terms of digital promotions and revenue generation via social media, it is critically based on the quality of the promotions, i.e., the quality of the photo or a video, and the level of engagement with judicious use of the description space and further utilization of hashtags. These parameters make a significant difference, especially if it is a product-based promotion in the sports sponsorship environment, like Nike-Lebron James ${ }^{(24)}$ or Virat Kohli-Hero MotoCorp ${ }^{(25)}$.

\section{A. Our bits and pieces on trends for Twitter (Figure. 1-19):}

Considering Olympic Games, 70-75\% of the overall Olympic Committee's revenue is generated from broadcasting rights ${ }^{(26)}, 2016$ Rio Olympic Games garnered 356,924 hours of massive coverage of the event across different platforms, out of which TV coverage was approx. 113,455 hours across 584 channels globally, digital coverage was close to 243,469 hours across 270 digitized platforms globally with additional $100+$ official social media Rights-Holding Broadcasters (RHB) ${ }^{(27)}$ recognized by the IOC with an estimated reach of about 7.2+ Billion impressions (video) across all social media platforms ${ }^{(27)}$. Furthermore, the source of revenue generated by the IOC between 2013-2016, as always have been broadcasters, and The Olympic Partners (TOP) programme contributing a sum of $\$ 5.16 \mathrm{Bn}$, i.e., $\$ 4.15 \mathrm{Bn}$, and over $\$ 1 \mathrm{Bn}{ }^{(27)}$ respectively.

Circling back to the NSFs of Australia, India, New Zealand and the USA, while keeping our analytical eye open for Australian NSF's official Twitter accounts, we have seen significant growth (Figure. 1-6). Except for a few NSFs neither showing growth nor decline in terms of the number of followers. Few of these governing bodies being, Australian Karate Federation with only 10 followers, Australian Taekwondo with only 1-2 followers, Croquet Australia with only 15 followers, Australian Flying Disc Association with 1100+ followers, Boxing Australia with 4500+ followers, Australian Weightlifting Federation having 1100+ followers, Australian Kendo Renmei having 1000+ followers, Archery Australia with 1100+ followers, Ice Skating Australia with 1100+ followers, Modern Pentathlon Australia with just 15-25 followers, Deaf Sports Australia having 1300+ followers, Diving Australia with 1200+ followers, Surfing Australia with 11,000+ followers, Gymnastics Australia having close to 15,000+ followers, Golf Australia with a massive fanbase of 23,000+ followers, Hockey Australia having 24,000+ followers, Rowing Australia with 11,000+ followers, and Athletics Australia with 27,000+ followers throughout our timeline of the data gathering process, i.e., between Dec 2020 - Mar 2021.

In New Zealand, the Kiwis have a very unique story to tell if we closely track and monitor the growth of NSFs using number of followers on their official Twitter account (Figure. 7-10), with a similar exception for a bunch of NSFs showing consistencies and inconsistencies in their own ways, especially if we consider the overall population of New Zealand, i.e., 5+ $\mathrm{Mn}^{(28)}$ as of $18^{\text {th }}$ May 2020. Few of such sport's governing bodies being AFL New Zealand with 1500+ followers, Bowls New Zealand with 1400+ followers, Equestrian Sports New Zealand having 1600+ followers, Special Olympics New Zealand with 1500+ followers, Squash New Zealand with 1200+ followers, Swimming New Zealand having 1500+ followers, Triathlon New Zealand with close to 3700+ followers, Softball New Zealand having 2300+ followers, and Climbing New Zealand with just about 100+ followers throughout our data gathering process, i.e., between Dec 2020 - Mar 2021. Cricket New Zealand stands out to be the most successful NSF with a growth rate of $\sim 3.8 \%$, i.e., from $464 \mathrm{k}+(0.46 \mathrm{Mn})$ to $481.2 \mathrm{k}+(0.48 \mathrm{Mn})$ followers in a span of 3 -months.

The Indian story has its variety of complications and a few positives. NSFs in the South Asian region of the world have a different set of challenges, particularly being the $2^{\text {nd }}$ most populated country in the world with $1.36 \mathrm{Bn}+$ people ${ }^{(29)}$, and we witnessed a massive 19 $\mathrm{Bn}+$ (viewing minutes) of watching and following multiple sporting disciplines ${ }^{(30)}$ across all immensely complicated geographic and political demographics. Surprisingly this is 35\% less because of the pandemic if compared to $29 \mathrm{Bn}+$ viewing minutes ${ }^{(30)}$ in 2019. Similar to Australia and New Zealand, there are a few governing bodies of sports showing consistencies and inconsistencies in terms of growth of followers on Twitter (Figure. 11-14), some of them being Billiards \& Snookers Federation of India with 1300+ followers, Squash Racket Federation of India having 1300+ followers and Table Tennis Federation of India having 1000+ followers throughout our data gathering process, i.e., between Dec 2020 - Mar 2021. Cricket, as expected, in India seems to be the front runner with a massive base of 13-14 Mn+ fans and followers, with a growth rate of approx. 5.4\% in a span of 3-months, particularly because of the historic win vs. Australia in the 2020-2021 season followed by a dominating performance against England in early 2021.

United States of America (USA)'s growth rate in terms of social media followers, particularly on Twitter is massive (Figure. 15-19) with of course a few NSFs with consistencies \& in-consistencies depending upon how we look at it. Some of these NSFs being USA Boccia with hardly 100+ followers, USA Wheelchair Rugby having close to 2400+ followers, USA Para-Cycling with 2300+ followers, USA Para Swimming with just about 1500+ followers, and USA Para Nordic Skiing having 1300+ followers throughout our data gathering process, i.e., between Dec 2020 - Mar 2021. When it comes to basketball, we all know the love people in America have for sports and eventually it shows via social media followers as USA Basketball has a massive $959 \mathrm{k}+(0.95 \mathrm{Mn})$ followers. But it is Team USA, who are leading consistently from the front with $1.9 \mathrm{Mn}+$ followers. Additionally, the USA is the only country among the four considered for this discussion, which has 10-NSFs whose Twitter accounts have 100,000+ followers (Figure. 19).

This publication is licensed under Creative Commons Attribution CC BY.

http://dx.doi.org/10.29322/IJSRP.11.06.2021.p11413

WWW.ijsrp.org 


\section{B. Our bits and pieces on trends for Facebook (Figure. 20-38):}

There are multiple theories wandering around in the open on how can social media platforms can/should be the primary tool for marketing, promotions and branding with significantly lesser dynamic investments, especially for start-up and relatively small, or midsized companies trying to utilize the full potential of sharing relevant and tactful information about the firms' values, beliefs, products and services and of course the top-management's view on recent trends \& hot topics in each targeted and segmented market(s). When it comes to sports, the social media \& digital content consumption market continuously fluctuates like our normal heartbeat on an ECG monitor. It's all those breathtaking moments on the field of play, be it some fantastic 3-pointers or slam dunks from Michael Jordan, Stephen Curry or Lebron James or Wimbledon 2019 Finals between Roger Federer and Novak Djokovic ${ }^{(31)}$, or watching the longest men's rally in Badminton between Nguyen (Vietnam) and Jorgensen (Denmark), or understanding the science behind trying to hit the badminton shuttle faster than $500 \mathrm{~km} / \mathrm{h}^{\left({ }^{32}\right)}$. It always comes down to mixing these breathtaking moments with the emotions \& sentiments of the fans and followers around the world (be it a team sport or individual athletes).

National Sports Federations in Australia, particularly using Facebook (Figure. 20-25) as a platform for sharing many of these emotionally connected sporting moments are having a fantastic time themselves, depending on their sizable population, i.e., close to 25.4 Mn people (2.54 Crore) ${ }^{(33)}$, and the ability to be transparent (to a limited extent of course). Similar to what we have for NSF's official Twitter accounts, a few federations have shown consistencies and in-consistencies strictly depending on how we look at them in the given moment be it the pandemic, or limitation of funds, and many more. For instance, Floorball Australia with just about 1100+ followers, Australian Fencing Federation with just over 3000+ followers, Australian Kendo Renmei having close to 1300+ followers, Disabled Wintersport Australia having just about 3100+ followers, Australian Weightlifting Federation with a consistent base of over 13,000+ followers, Badminton Australia with a substantial base of 11,000+ followers, Disability Sports Australia having just about 4100+ followers, Australian Ice Racing having a minor presence with close to 1000+ followers on Facebook throughout our data gathering process, i.e., between Dec 2020-Mar 2021. Cricket found its way into Australia, because of the history it has in various regions with an enormous growth rate of $\sim 3.4 \%$, from $858 \mathrm{k}+(0.85+\mathrm{Mn})$ to $887 \mathrm{k}+(0.87+\mathrm{Mn})$ in a span of 3 -months. Australian Football League is leading from the front on Facebook for Australian Sports Business, with a consistent 1.19 Mn+ followers.

National Sports Federations in New Zealand, particularly using Facebook (Figure. 26-28), have shown a considerable amount of growth in terms of number of followers, with of course some of them exhibiting consistencies \& in-consistencies based on how we want to look at them at the given moment be it the economic dependency or building and maintaining diplomatic relationships with the neighbouring counterparts. Some of such NSFs being Karate New Zealand with just over 1500 followers, Deaf Sports Federation New Zealand having close to $1200+$ followers, Ice Speed Skating New Zealand having just about 1100+ followers, Lacrosse New Zealand (Men) approx. having 2000+ followers, Triathlon New Zealand however has a substantial base of about $11,000+$ followers, followed by Swimming New Zealand with a base of about 12,000+ followers and Volleyball New Zealand have a consistent base of $13,000+$ followers. Netball New Zealand however, stands out with a massive following approx. 71,000+ followers on Facebook throughout our data gathering process, i.e., between Dec 2020 - Mar 2021. New Zealand Olympic Committee surprisingly witnessed a decline, yet manages to have $289 \mathrm{k}+(0.28+\mathrm{Mn})$ followers, but Cricket leads from the front in New Zealand as well with a massive follower base of $2.17 \mathrm{Mn}+$, i.e., a stunning growth rate of $\sim 3.4 \%$ in a span of 3 -months.

National Sports Federations in India, particularly using Facebook (Figure. 29-32), have been doing well in terms of consistent growth, with of course some of them exhibiting in-consistencies based on how we want to look at them in the given moment be it the pandemic dependency, or maintaining defensive relationships with some of the neighbouring countries, particularly communist by nature to be honest. Some of these NSFs are Indian Polo Association with hardly 40+ followers, All India Tennis Association having 1300+ followers, Fencing Association of India whose President is the Secretary-General of the Indian Olympic Association (IOA) have just over $1800+$ followers, Handball Federation of India have close to 1300+ followers, Squash Rackets Federation of India have just about 10,000+ followers, Paralympic Committee of India have a base of 11,000+ followers and Billiards \& Snookers Federation of India (Cue Sports) have an approx. base of 14,000+ followers on Facebook throughout our data gathering process, i.e., between Dec 2020 - Mar 2021. All India Football Federation (AIFF) however, has a massive reach with $1.3 \mathrm{Mn}+$ followers, i.e., <1\% of the entire Indian population, along with Hockey India having close to $4 \mathrm{Mn}+$ followers consistently, i.e., <1\% of the Indian population. Cricket has a special place in the Indian sub-continent and it is sure they worked on its presence on Facebook with a base of 28.5 Mn+ followers, i.e., $\sim 2.1 \%$ of the entire Indian population. It means, nearly $34 \mathrm{Mn}$ people ( 2.5\% overall) follow Football, Hockey and Cricket in the Indian sub-continent on Facebook.

National Sports Federations in the United States of America, have been using Facebook (Figure. 33-38) exceptionally well, with of course some of them exhibiting consistencies \& in-consistencies based on how we want to look at them at the given moment, such as USA Boccia with just about 950+ followers, USA Para Snowboarding having nearly 300+ followers, USA Golf with close to 2600+ followers, USA Skateboarding having close to 1650+ followers, USA Para Alpine Skiing with about 3000+ followers and USA Para Nordic Skiing having just about 2900+ followers. Among all the four countries considered for this detailed study of social media accounts \& respective followers, 12-NSFs (Figure. 34) in USA have followers between 10,000 - 30,000+ followers, 10-NSFs (Figure. 35) in USA have followers between 30,000 - 80,000+ followers, 17-NSFs (Figure. 36) in USA have followers between $100,000-300,000+$ followers, 7-NSFs (Figure. 37) in USA have followers between 300,000 - 600,000+ followers and 3-NSFs 
(Figure. 38) have followers between $2 \mathrm{Mn}+-4 \mathrm{Mn}+$ followers, i.e., USA Soccer $<1 \%$ of the entire population of USA ( 328.2 Mn) ${ }^{(34)}$, Team USA approx. $1.2 \%$ of the entire population and USA Basketball $\sim 1.25 \%$ of the entire population.

Watching Australia, New Zealand, United States and most other countries handling the sports administration and governance, for an Indian citizen it always like, quote "the grass is always greener on the other side!". But Jessica Morrison (OLY), an Australian Rower who represented Australia at the Rio 2016 Olympic Games, has a very interesting thought as she believes in something that Nicky Gumbel said, "If the grass seems greener, it's probably AstroTurf". That being said, it is not always necessary that if something that looks very promising and interesting on the other side of our visionary spectrum is always the best or works perfectly. In our managerial and professional opinion, it is the challenges or setbacks which we (as an individual or organization) overcome, help us in defining the way forward. However, it is essential that we are carefully aware of what we have been doing all these years, to ensure we are on the right track of development both professionally and personally, as an individual as well as an organization (NSFs or Sports Governing Bodies in this case). Steven Goldfried, who was the Digital Content Strategy Manager for Houston Rockets ${ }^{(35)}$, and currently is the Sr. Manager, Global Digital and Social NBA at 2K while presenting at the MIT Sloan Sports Analytics Conference (SSAC) 2019 shared that, quote "generating only organic growth via Facebook and Instagram in particular, is a myth" (35), but it really does help the organizations keep a track of content, information or data that is being created for people (specific to sports) in the market to consume and stay connected with the player(s), franchise(s) or National team(s).

Social media platforms such as Twitter, Facebook ${ }^{(35)}$, Instagram ${ }^{(35)}$, YouTube are helping governing bodies of sports, ISFs, NSFs, sports franchises, etc. to have a detailed profile of their fans, followers ${ }^{(5)}$ and viewers, in terms of geographical information, demographic profiling of user/fan base, and the most horrifying (from a consumers/fans perspective), the psychographic profiling and personal preference collection. Steven Goldfried also feels that social media growth can easily help us immediately spread the information, content or data to the masses in the open, but it would not be long term. He believes, that at certain point we might be able to make a certain fact or information viral ${ }^{(35)}$ but soon enough it will die down once its left open to all in the market. Particularly, because we aren't or maybe cannot follow up on that story, fact or information for relevant reasons. It is important for the organizations (specific to sports in this case, i.e., ISFs, NSFs, etc.) to have the flexibility of developing, moulding, and re-iterating their goals, objectives and strategic directives for effectively reaching out (in terms of engagement organically) to their fans, followers (5) and viewers also termed as audience(s) via respective social media platforms using creativity as well as following their vision, mission and values fastened as a strong and relevant message. For example, everyone taking a stand against racial abuse on social media recently ${ }^{(37)(38)}$ or wearing black arm-bands and take a knee in Black Lives Matter gesture ${ }^{(39)}$.

\section{Our bits and pieces on trends for Instagram (Figure. 39-58):}

In recent years, social media influencing has been the choice of markets as well as the consumers too, both sell their products and services (a manufacturer perspective) and buy or research about the product or service (a customer's perspective). The influencer marketing and promotions markets have been growing at a significant rate (YoY) globally ${ }^{(39)}$ from $\$ 6.5 \mathrm{Bn}+$ in 2019 , to $\$ 9.7 \mathrm{Bn}+$ in 2020 to $\sim \$ 13.8 \mathrm{Bn}+$ in $2021^{(40)}$ and it is expected to cross the worth-mark of $\$ 15 \mathrm{Bn}+$ by $2022^{(41)}$. Instagram seems to be a perfect tool not just for the sellers, marketers or promoters (in this case NSFs or Sports Governing Bodies), but also for the consumers who are willing to be part of the promotional campaigns and marketing ideas' and claim monetary benefits in the process.

In sports, the two most influential aspects are the athletes and the sports itself, i.e., the most efficient way of labelling the influencers (in this case athletes \& the sports itself) will be the amount of reach each of them can help us generate, and how can we create a deep connection, in terms of our targeted and segmented markets with the fans, followers and viewers. As per the 2020 reports, $87 \%$ of marketers or campaigners prefer Instagram as the primary tool for engaging ${ }^{(39)}$, 2021 reports show that $79 \%$ chose Instagram for marketing ${ }^{(43)}$ and promotional campaigns ${ }^{(41)}$ primarily because a significant amount had to be spent on other relevant social media ${ }^{(44)}$ platforms to stay connected with the market and the consumers due to adverse effects because of the lockdown.

Now if we circle back to the National Sports Federations in Australia, particularly using Instagram (Figure. 39-44), they have had substantial growth with a few NSFs showing uniformities and irregularities, such as Australian Ice Racing with just about 400+ followers, Australian Kendo Renmei having only 230+ followers, Australian Outrigger Canoe Racing Association with just 200+ followers, Croquet Australia having just 130+ followers, Modern Pentathlon Australia with just about 250+ followers, Archery Australia having close to 1000+ followers, Artistic Swimming Australia having just about 1800+ followers, Judo Federation of Australia having close to 1100+ followers, Australian Karate Federation having just about 1500+ followers, Badminton Australia with 1500+ followers, Floorball Australia having close to 1200+ followers and Skate Australia having close to 1300+ followers. Australian Olympic Committee (AOC) however, is one of the three organizations (sports specific) which has a fan base of 100,000+ followers, the other two being Australian Football League and Cricket Australia with 800,000+ followers (Figure. 44).

National Sports Federations in New Zealand, particularly on Instagram (Figure. 45-48), have had substantial presence on this platform, with of course a few showing uniformities \& irregularities, such as the Deaf Sports Federation NZ having just about $170+$ followers, Fencing NZ with just about 370+ followers, Gliding NZ with $\sim 350+$ followers, Karate NZ having just about 140+ followers, AFL NZ with just 1500+ followers, Badminton NZ having 1400+ followers, Bowls NZ with just about 1000+ followers, 
Baseball NZ having close to 2000+ followers, Yachting NZ having a consistent growth to about 1400+ followers and Lacrosse NZ (Men) having just about 1700+ followers. NZ Olympic Committee on Instagram have a massive following with $\sim 47,000+$ followers which is fantastic considering their Pre-Tokyo 2020 fan and athlete engagement plans, but Cricket New Zealand is leading from the front on Instagram, with a growth rate of $\sim 12.2 \%$, i.e., $856 \mathrm{~K}+$ to $960 \mathrm{~K}+$ followers between Dec 2020 - Mar 2021.

National Sports Federations in India, particularly on Instagram (Figure. 49-52), have had a stable momentum except a few NSFs showing uniformities and irregularities such as Paralympic Committee of India with just 1000+ followers, Fencing Association of India also with $\sim 1000+$ followers, Table Tennis Federation of India again with just about 1100+ followers, Volleyball Federation of India having only 300+ followers. However, Hockey India which was the National Sports of India (emphasis on 'was) has a substantial presence with $86 \mathrm{~K}+$ followers and a growth rate of $\sim 3.1 \%$, Khelo India the sports development scheme (allegedly) initiated by MYAS and SAI has a base of $\sim 102,000+$ followers and All India Football Federation (AIFF) again sets the right example with a base of $900,000+$ followers and a growth rate of $\sim 3.4 \%$. Cricket in India, cannot be left behind in terms of follower's base, i.e., $16+$ $\mathrm{Mn}$ and a growth rate of $\sim 15.3 \%$.

The most crucial thing as an organization in terms of measuring accountability, managerial approach and value of successful growth, specifically the IOA \& PCI have to realize is that any of these social media platforms, i.e., Twitter, Facebook, Instagram, YouTube are not for revealing the first level information, data or content. Any such first level information, data or content has to be first ( $1^{\text {st }}$ ) released/revealed via an official press release not via media organizations or press bureaus. This official release should also be immediately made available on respective websites so the media organization in multiple capacities will have access for referencing and acknowledgement. Following the press release, all the social media platforms can be further used to substantially increase the reach and gain significant attention, assuming that many of the fans, followers ${ }^{(5)}$ and viewers won't have access to the website, or in many cases will not have registered social media accounts (personal or professional). There has to be a proper inter-linked chain of processes that has to be followed to reveal any official information be it about the athletes, officials, events, internal managerial changes ${ }^{(29)}$ or development schemes/programs ${ }^{(29)}$.

National Sports Federations in USA, particularly on Instagram (Figure. 53-58), just like on Twitter and Facebook is showing tremendous potential with a just a few NSFs showing uniformities and irregularities, such as USA Boccia having just about 300+ followers, USA Para Snowboarding with 500+ followers however, USA Handball witnessed a substantial growth of $\sim 31 \%$ between Dec 2020 - Mar 2021, USA TT \& Para TT, USA Water Ski/Wakeboard and USA Bobsled \& Skeleton have been consistent with $\sim 12,000+$ followers respectively, USA Track Speedskating also have been consistent having a base of $\sim 13,200+$ followers. The most interesting aspect for us has been the fact that 20-NSFs in USA have had base of 100,000+ followers (Figure. 57, 58), such as Team USA being the $2^{\text {nd }}$ most followed Instagram account with about $838,000+$ followers, but has been declining ( $-1.64 \%$ ) b/w Dec 2020 Mar 2021, USA Baseball consistently maintaining a base of 523,000+ followers, USA Gymnastics being the $3^{\text {rd }}$ most followed Instagram account have a massive base of 760,000+ followers, USA Swimming are $5^{\text {th }}$ on the list of most followed Instagram accounts with a base of 553,000+ followers, USA Volleyball and Sitting Volleyball are $4^{\text {th }}$ on the list of most followed Instagram accounts with a base of $\sim 620,000+$ followers and finally USA Basketball leading from the front on the list of most followed Instagram accounts has a base of $3.2 \mathrm{Mn}+$ followers consistently.

\section{Our bits and pieces on trends for YouTube (Figure. 59-77):}

Social media environment today is a swiftly mutable ${ }^{(44)}$ with multiple players in the market, content consumption techniques and the preferences of people based on demographics, language, age and many other parameters that are responsible for what we see and what we don't be it television, social media accounts, online streaming platforms or OTT platforms. Social media platforms have been universally accepted as the prodigious tools for branding or brand management (44) as well as content, information or data consumption. The companies, brands or organizations (specific to NSFs or governing bodies of sports) want the people (also termed as fans, followers or viewers) to come to them and learn more about the recent trends or, what they do?, explicitly depending on each of their personal preferences.

It is critical for the companies, brands or organizations (specific to NSFs or governing bodies of sports) to maintain a balance between the type of engagement on each of these platforms, primarily because social media in this high-performance era of sports has been responsible for driving fan engagement, sponsorship activities (35)(44), branding and marketing campaigns, enabling partnership opportunities ${ }^{(35)(44)}$ for the business to become self-sustainable, data driven and have robust processes for respective long-term growth plans and strategies. YouTube in our personal and professional opinion, gives us an opportunity to be presentable in the market, because a human brain is able to process visual content at an incredibly high speed, in-fact 60,000 times faster than text ${ }^{(45)}$.

A few interactions or involvement in the engagement strategies on the social media platforms, specifically via our smartphones have exhibited sustained neural changes ${ }^{(46)}$ in cortical regions associated with sensory and motor processing units of the human body. The social media platforms evidently are the center stage for nearly endless grasping power ${ }^{(46)}$ of new information and complex processes, both on \& off the field. Therefore, growth on YouTube gets even more interesting. Looking at NSFs in Australia using YouTube (Figure. 59-64) to capitalize on their social engagement plans and video-based initiatives, we can see that a few NSFs showing 
uniformities and irregularities, such as Artistic Swimming Australia, Disabled Wintersport Australia and Deaf Sports Australia having just 10-12 subscribers, Australian Billiards \& Snooker Council, Australian Taekwondo and Bocce Australia having <10 YouTube subscribers. BMX Australia/AusCycling had 3000+ subscribers but we couldn't retrieve data b/w Feb-March 2021 because the account was made Private. However, Rugby Australia has been consistently garnering 73,000+ subscribers and lastly, we can see that Australian's love the game of "footy" as the Australian Football League (AFL) stands tall with 206,000+ subscribers.

NSFs in New Zealand have a very different story of using YouTube (Figure. 65-67) to capitalize on their fan engagement and videobased marketing and advertising initiatives, we can see that a few NSFs showing uniformities and irregularities, such as Golf New Zealand having just 13 subscribers, AFL New Zealand and Surfing New Zealand with just 150+ odd subscribers, Basketball New Zealand however, showed some organic and consistent growth by having $~ 1200+$ subscribers and a growth rate of $\sim 4.4 \%$, Gymnastics New Zealand also consistently maintained $\sim 1400+$ subscribers. Cricket New Zealand once again leads from the front in terms of sports social media growth in New Zealand with a massive base of $\sim 936,000+$ subscribers (growth rate of $\sim 77 \%$ ), i.e., from $530 \mathrm{~K}+$ to 936K+ subscribers between Dec 2020 - Mar 2021.

Association of National Olympic Committees (ANOC) on $10^{\text {th }}$ May 2021 shared some statistics via Twitter that Indian Olympic Association (IOA), Comité Olímpico Mexicano (COM) also known as Mexican Olympic Committee, Japanese Olympic Committee (JOC), Saudi Arabian Olympic Committee and Comité National Olympique Marocain (CNOM) also known as Moroccan Olympic Committee have quoted: (47) "experienced the largest follower growth across Facebook, Twitter, Instagram and YouTube in April". This gave us an opportunity to evaluate the growth rate of each of the social media accounts (between Dec 2020 - Mar 2021) of the Indian Olympic Association (IOA).

The results show that IOA's follower's growth rate on Twitter has been $\sim 10.6 \%$, on Facebook the follower's growth rate has been $<1 \%$, and on Instagram, the follower's growth rate has been $\sim 24 \%$. For NSFs in India having official YouTube accounts (Figure. 68 70), the story seems to change drastically if we strike Cricket (BCCI) out of the equation along with the Indian Olympic Association (IOA), as they do not have an officially active YouTube account yet. NSFs like the All India Tennis Association (AITA) hardly managed to get $\sim 35+$ subscribers, Indian Polo Association has just about $85+$ subscribers, Rowing Federation of India hasn't seen any growth \& have $\sim 50$ subscribers, Table Tennis Federation of India seems to follow the others with just about $60+$ odd subscribers. Paralympic Committee of India (PCI) has seen some growth having 1200+ subscribers along with Indian Rugby Football Union also known as Rugby India which has managed 2000+ subscribers between Dec 2020 - Mar 2021.

When it comes to NSFs in the United States of America (USA), they rather have a more interesting perspective when it comes to having an official YouTube channel (Figure. 71-77), except a few NSFs showing uniformities and irregularities, such as USA Canoe/Kayak \& Paracanoe with just about 30+ subscribers, USA Skateboarding having 50+ subscribers, USA Biathlon has about $90+$ subscribers. USA Water Polo, however, has a consistent base of 11,500+ subscribers, and so do USA Weightlifting with about $12,300+$ subscribers. Team USA remains the $3^{\text {rd }}$ most followed YouTube accounts with about 221,000+ subscribers and a growth rate of $\sim 19 . \%$, USA Gymnastics claims the $2^{\text {nd }}$ spot with $385,000+$ subscribers and a growth rate of $\sim 4.6 \%$ and USA Soccer clinches the $1^{\text {st }}$ spot with a massive base of 405,000+ subscribers and a growth rate of $\sim 1.8 \%$ between Dec 2020 - Mar 2021.

\section{E. Overall perspective on trends for having strategically aligned social media accounts:}

We as Sports Management Professionals and most notably fans, followers and enthusiasts ${ }^{(5)}$ of multiple dimensions and disciplines of Sports as well as its business, believe that there should be a sophisticated, centralized, strategically aligned and well managed and monitored system for content/information/data management and digitization of sports specific activities, campaigns, schemes, programs or initiatives ${ }^{(29)}$ in this high-performance era of athleticism. Everyone these days is inspired and is motivated (intrinsic or extrinsic) to follow the mottos of International Olympic and Paralympic Games, i.e., Citius - Altius - Fortius meaning Faster - Higher Stronger ${ }^{(48)}$, and Spirit in Motion ${ }^{(49)}$ which represents the resilient strength of character of every athlete.

It is the inefficiency and negligence and stubbornness of not having or trying to have a system in place, without being politically and self-righteous about the fact that there are people willing to be part of this dynamically organized and managed system who have the ability and resources to try and efficiently manage the system and in the process work towards adapting a policy of continuous evolution, which requires a much-needed sense of curiosity and most importantly an in-depth knowledge, passion and understanding of global sports ecosystem. 


\section{Figures \& DATA REPRESENTATION}

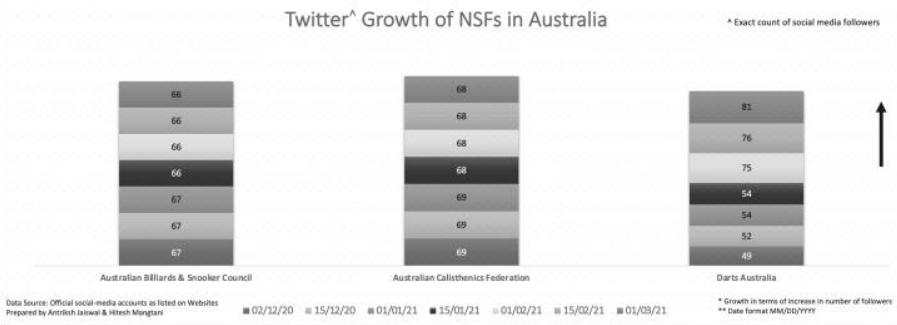

Figure 1. Social media dynamics of National Sports Federations $\mid$ Twitter (Australia) growth between Dec 2020 - Mar 2021.

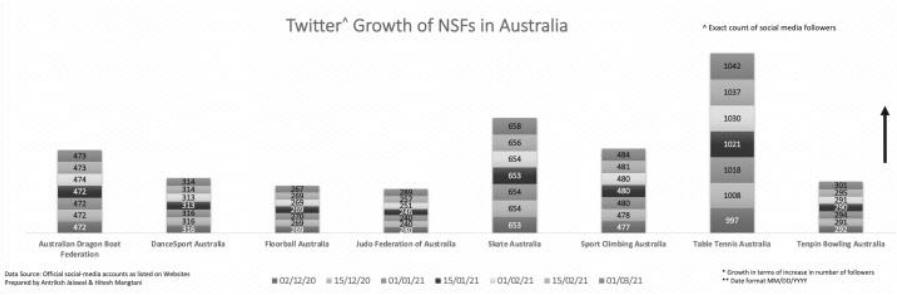

Figure 2. Social media dynamics of National Sports Federations | Twitter (Australia) growth between Dec 2020 - Mar 2021.

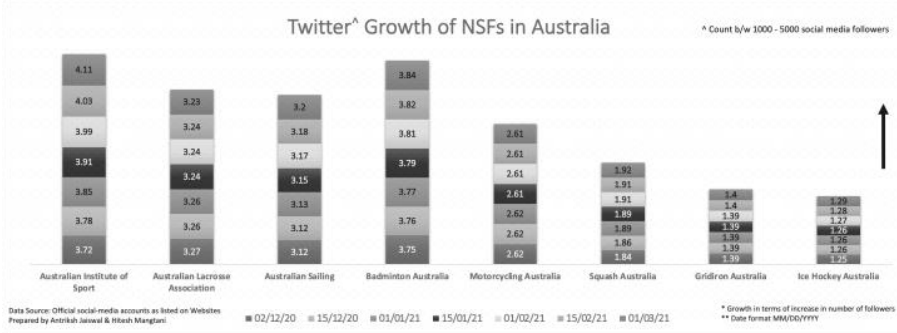

Figure 3. Social media dynamics of National Sports Federations $\mid$ Twitter (Australia) growth between Dec 2020 - Mar 2021.

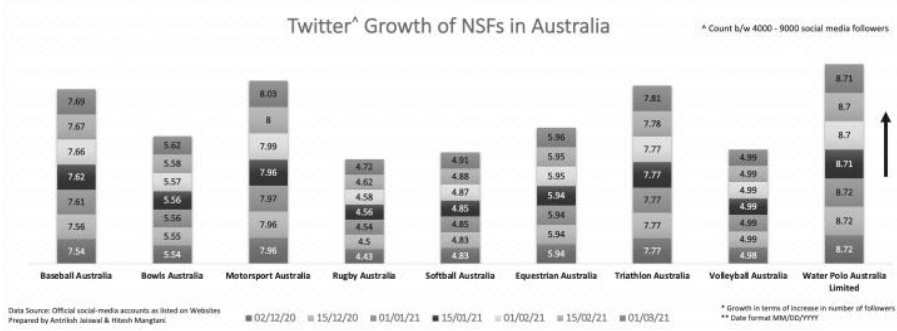

Figure 4. Social media dynamics of National Sports Federations | Twitter (Australia) growth between Dec 2020 - Mar 2021.

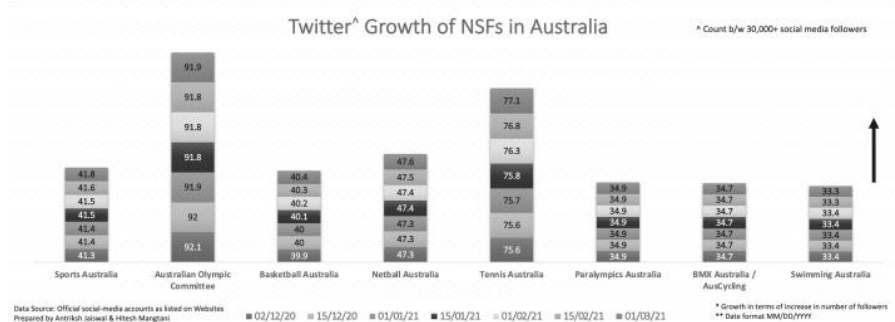

Figure 5. Social media dynamics of National Sports Federations $\mid$ Twitter (Australia) growth between Dec 2020 - Mar 2021.

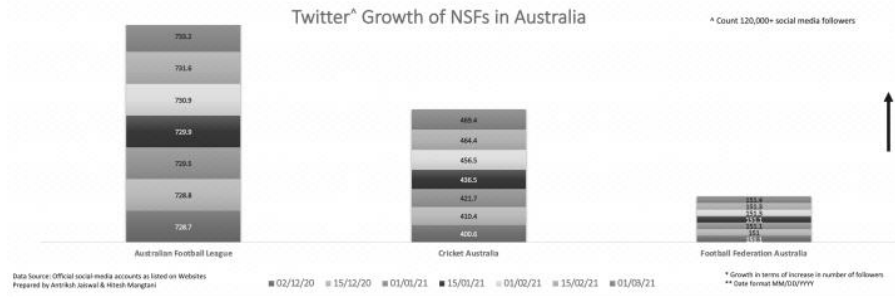

Figure 6. Social media dynamics of National Sports Federations $\mid$ Twitter (Australia) growth between Dec 2020 - Mar 2021.

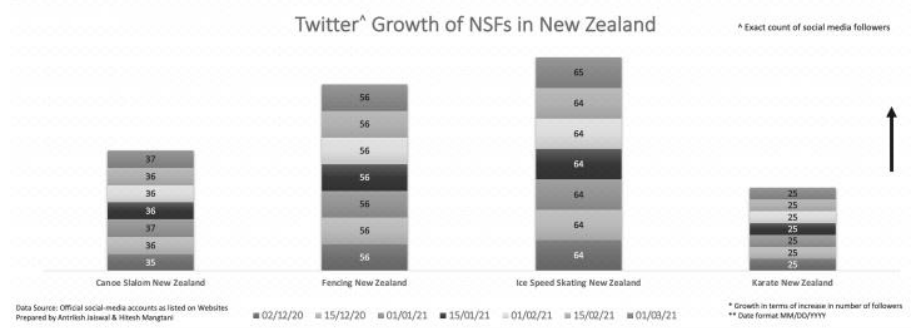

Figure 7. Social media dynamics of National Sports Federations $\mid$ Twitter (New Zealand) growth between Dec 2020 - Mar 2021.

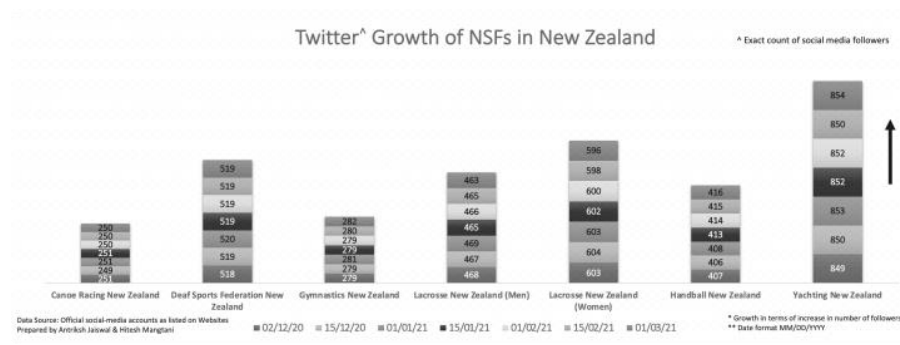

Figure 8. Social media dynamics of National Sports Federations $\mid$ Twitter (New Zealand) growth between Dec 2020 - Mar 2021.

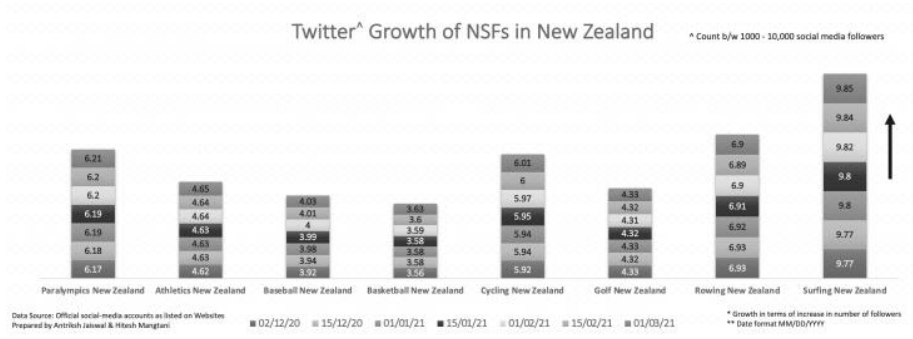

Figure 9. Social media dynamics of National Sports Federations $\mid$ Twitter (New Zealand) growth between Dec 2020 - Mar 2021

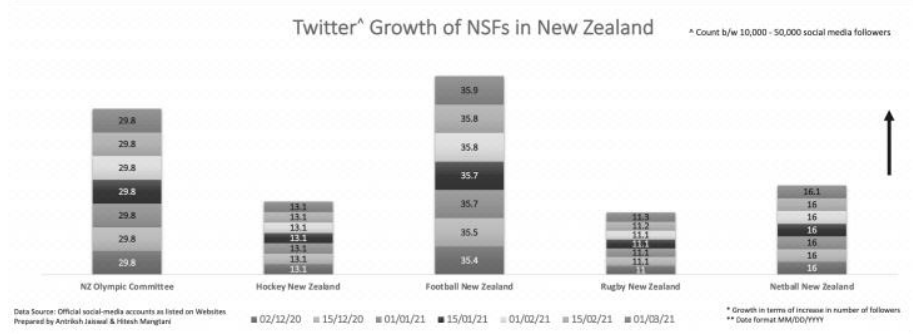

Figure 10. Social media dynamics of National Sports Federations | Twitter (New Zealand) growth between Dec 2020 - Mar 2021. 


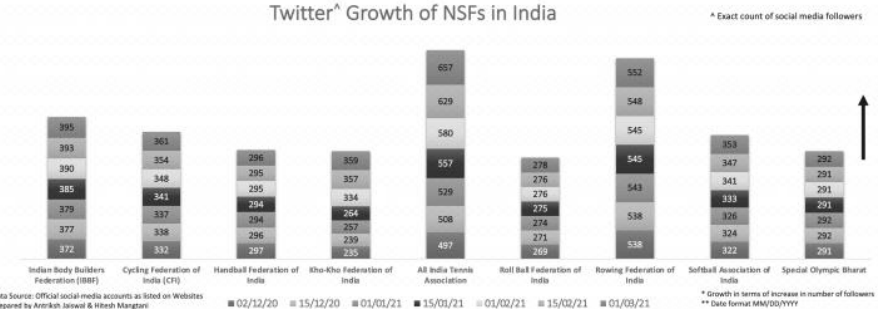

Figure 11. Social media dynamics of National Sports Federations $\mid$ Twitter (India) growth between Dec 2020 - Mar 2021

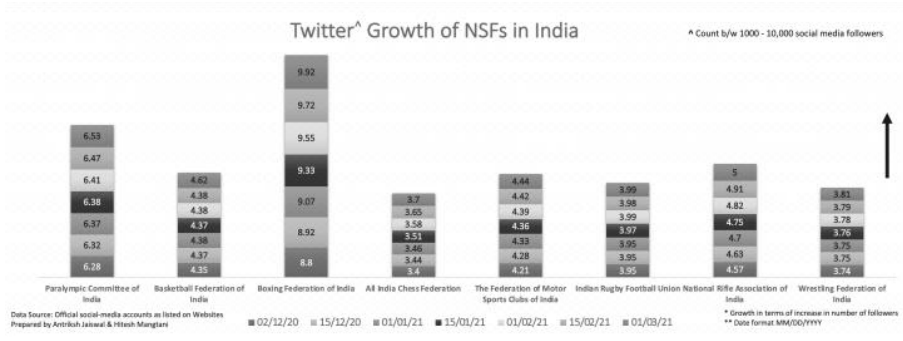

Figure 12. Social media dynamics of National Sports Federations $\mid$ Twitter (India) growth between Dec 2020 - Mar 2021

Twitter` Growth of NSFs in India

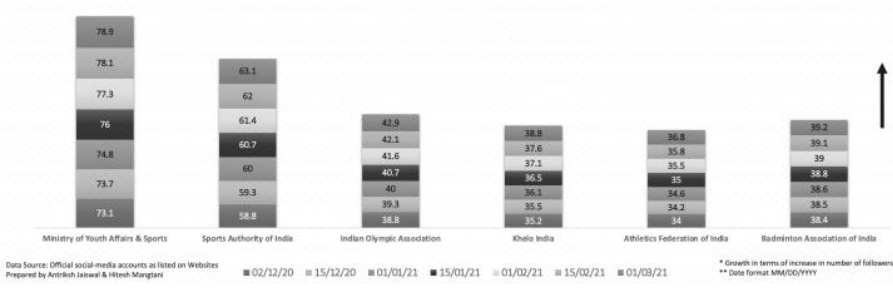

Figure 13. Social media dynamics of National Sports Federations $\mid$ Twitter (India) growth between Dec 2020 - Mar 2021.

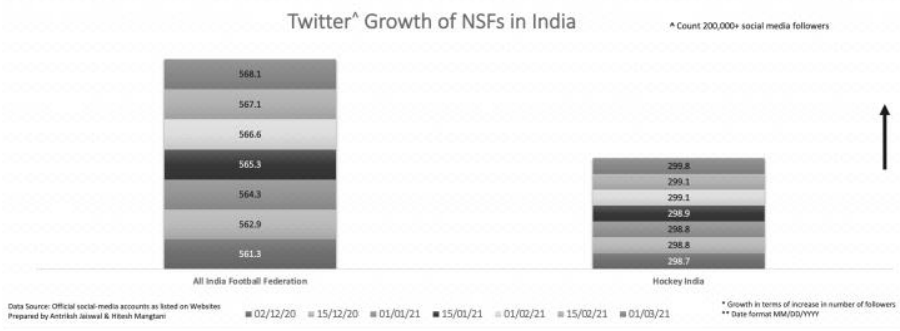

Figure 14. Social media dynamics of National Sports Federations $\mid$ Twitter (India) growth between Dec 2020 - Mar 2021.

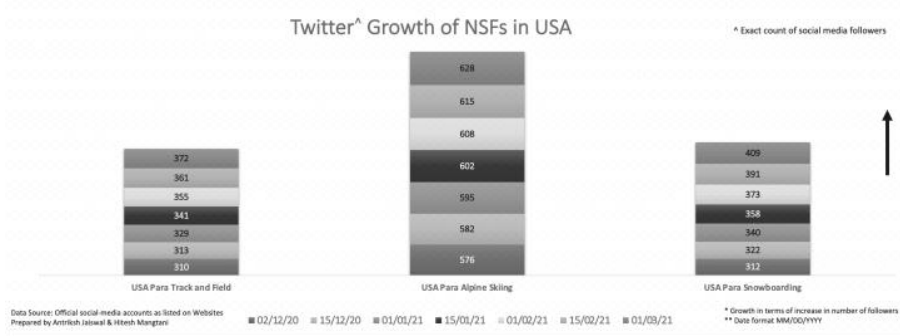

Figure 15. Social media dynamics of National Sports Federations | Twitter(USA) growth between Dec 2020 - Mar 2021

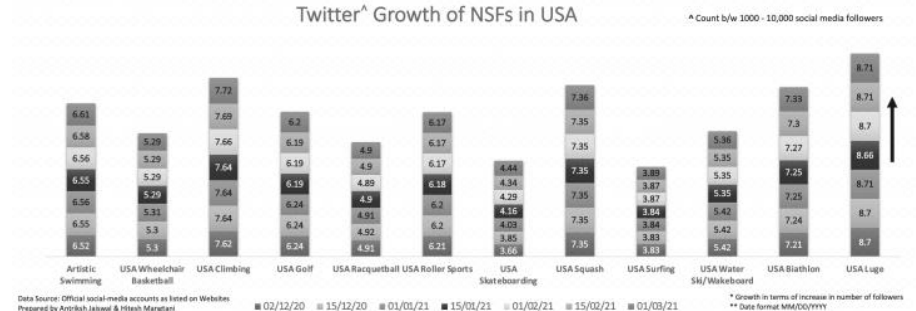

Figure 16. Social media dynamics of National Sports Federations | Twitter(USA) growth between Dec 2020 - Mar 2021.

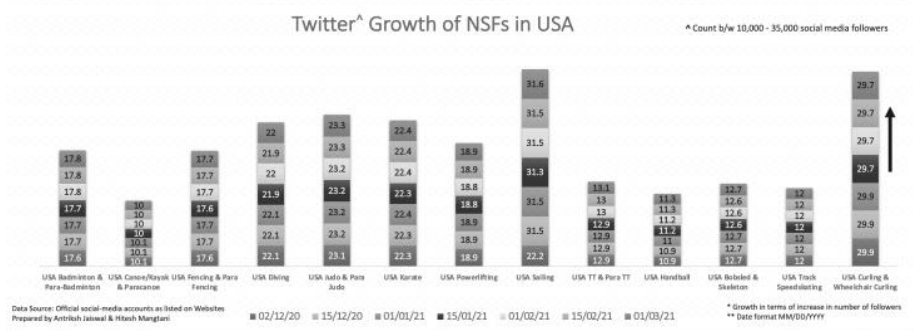

Figure 17. Social media dynamics of National Sports Federations $\mid$ Twitter (USA) growth between Dec 2020 - Mar 2021.



Figure 18. Social media dynamics of National Sports Federations $\mid$ Twitter (USA) growth between Dec 2020 - Mar 2021

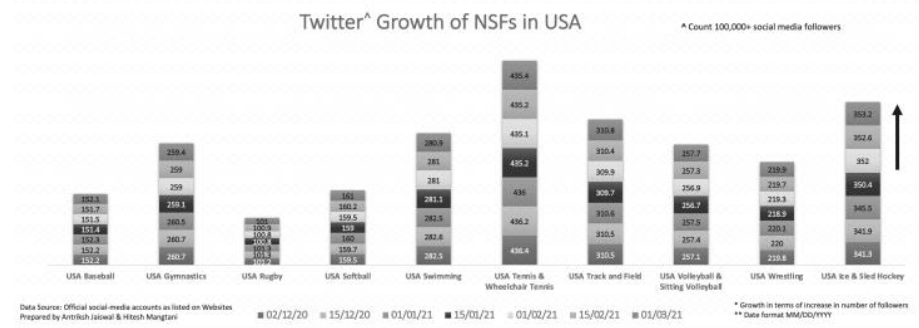

Figure 19. Social media dynamics of National Sports Federations $\mid$ Twitter (USA) growth between Dec 2020 - Mar 2021.

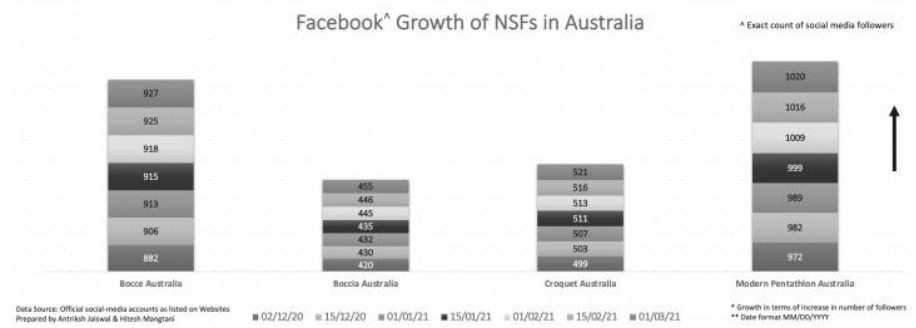

Figure 20. Social media dynamics of National Sports Federations | Facebook (Australia) growth between Dec 2020 - Mar 2021. 


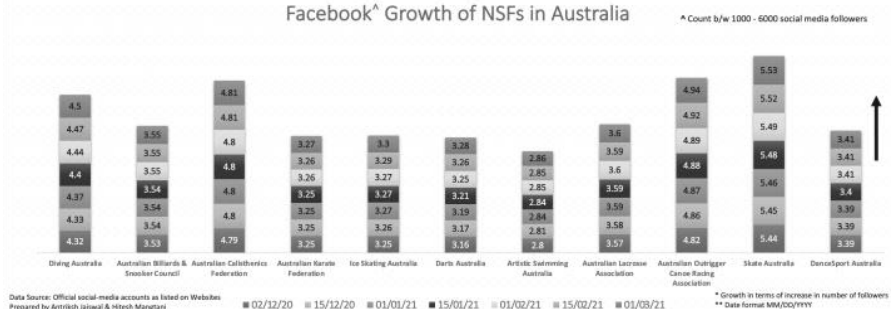

Figure 21. Social media dynamics of National Sports Federations $\mid$ Facebook (Australia) growth between Dec 2020 - Mar 2021.

Facebook^ Growth of NSFs in Australia

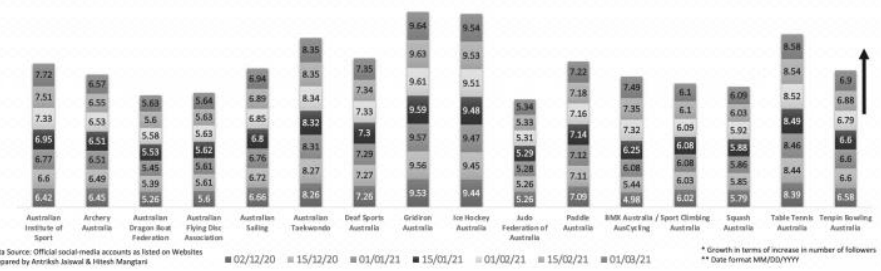

Figure 22. Social media dynamics of National Sports Federations $\mid$ Facebook (Australia) growth between Dec 2020 - Mar 2021.

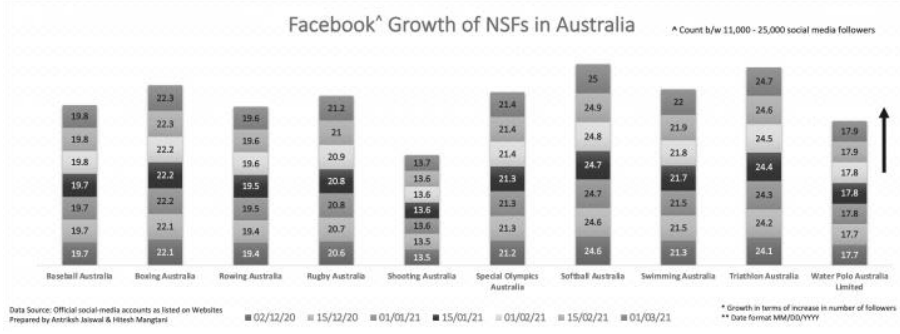

Figure 23. Social media dynamics of National Sports Federations $\mid$ Facebook (Australia) growth between Dec 2020 - Mar 2021.

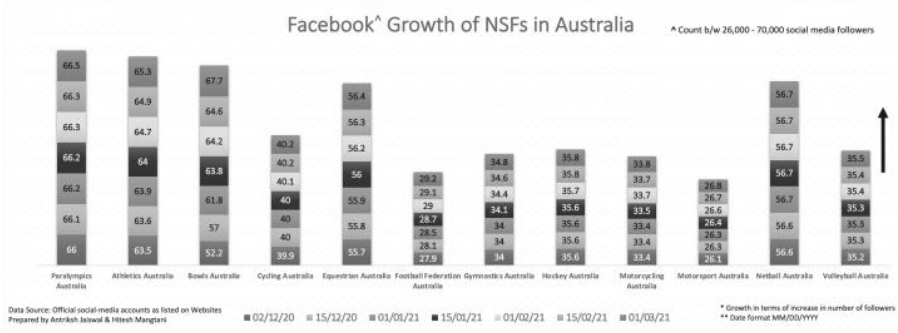

Figure 24. Social media dynamics of National Sports Federations | Facebook (Australia) growth between Dec 2020 - Mar 2021

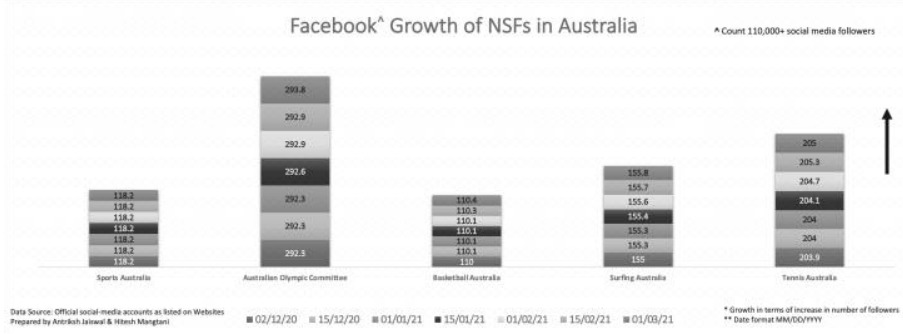

Figure 25. Social media dynamics of National Sports Federations | Facebook (Australia) growth between Dec 2020 - Mar 2021.

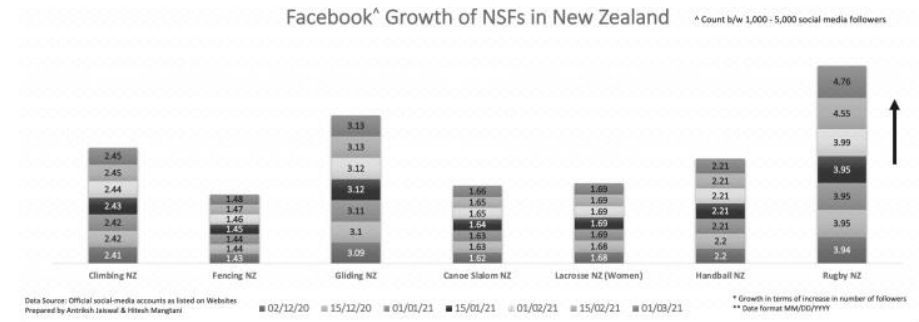

Figure 26. Social media dynamics of National Sports Federations | Facebook (New Zealand) growth between Dec 2020 - Mar 2021.

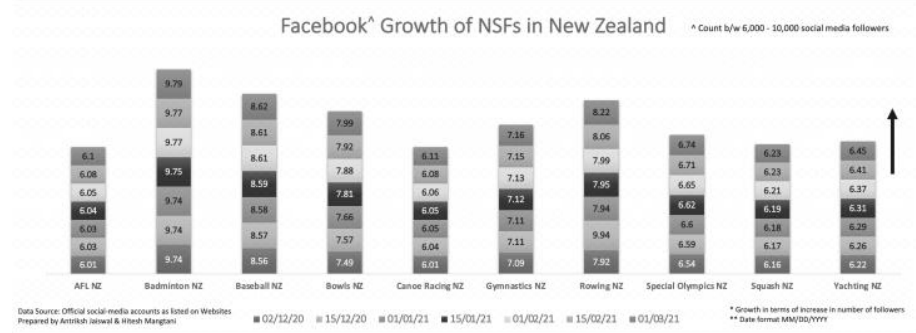

Figure 27. Social media dynamics of National Sports Federations | Facebook (New Zealand) growth between Dec 2020 - Mar 2021.

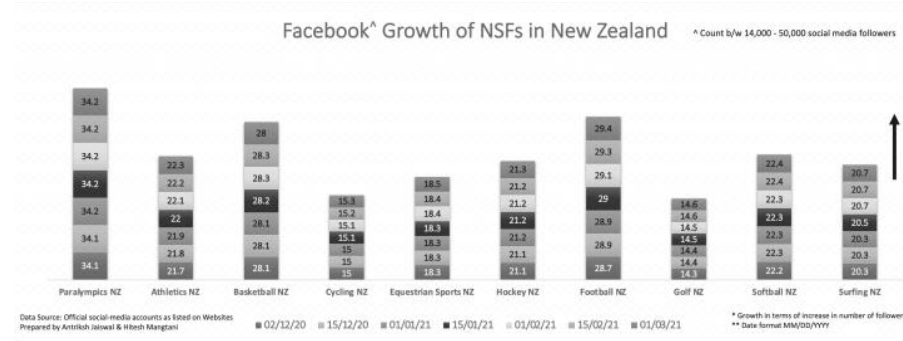

Figure 28. Social media dynamics of National Sports Federations $\mid$ Facebook (New Zealand) growth between Dec 2020 - Mar 2021.

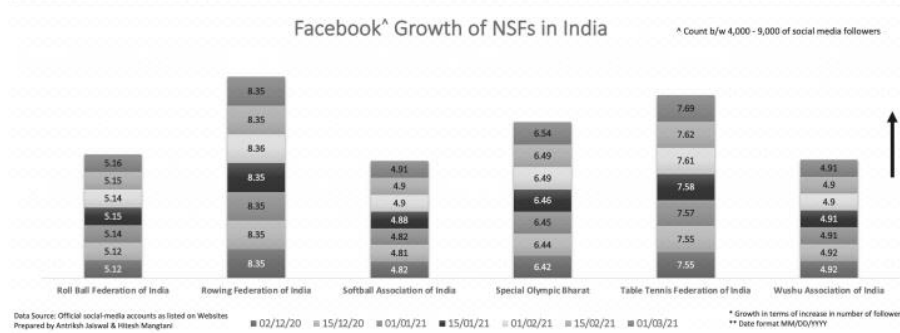

Figure 29. Social media dynamics of National Sports Federations $\mid$ Facebook (India) growth between Dec 2020 - Mar 2021.

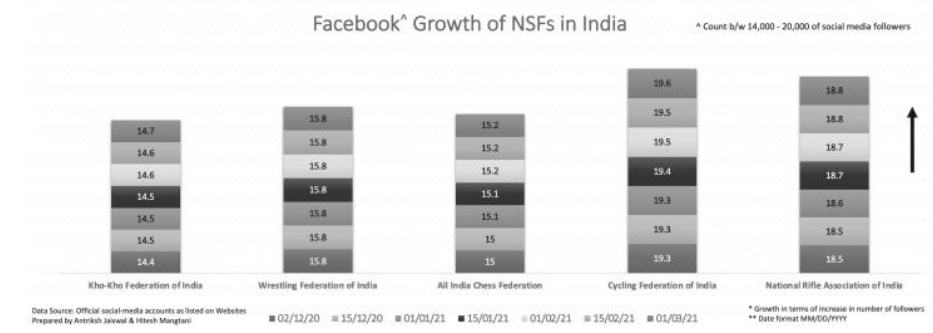

Figure 30. Social media dynamics of National Sports Federations | Facebook (India) growth between Dec 2020 - Mar 2021. 


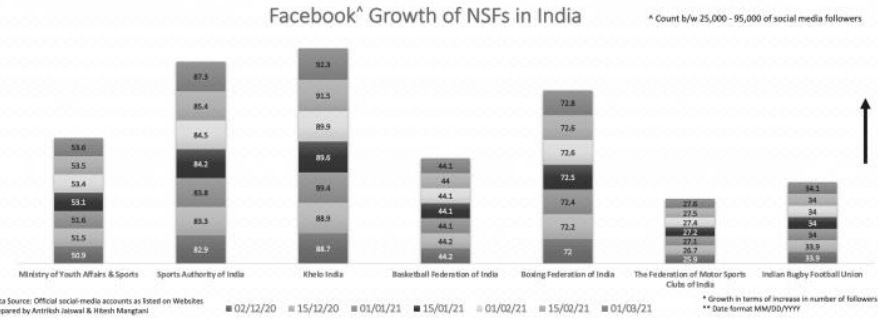

Figure 31. Social media dynamics of National Sports Federations $\mid$ Facebook (India) growth between Dec 2020 - Mar 2021.

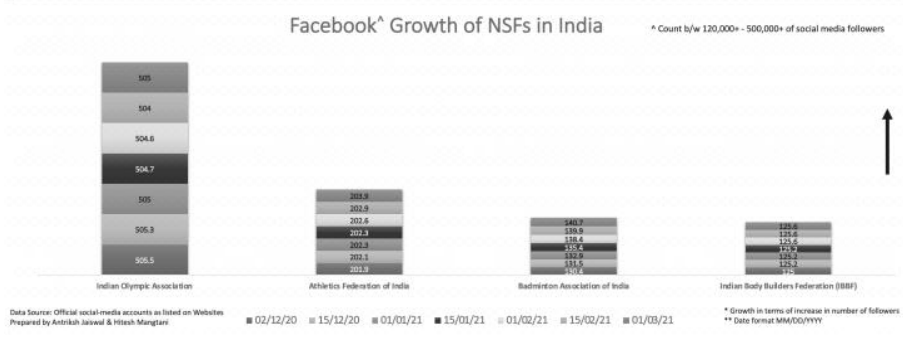

Figure 32. Social media dynamics of National Sports Federations | Facebook (India) growth between Dec 2020 - Mar 2021.

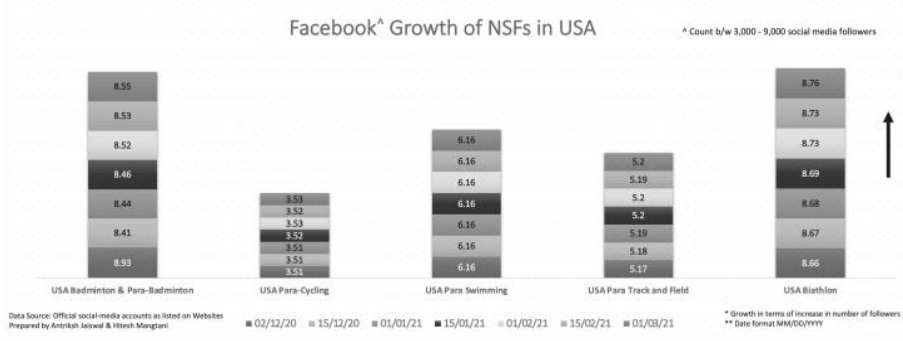

Figure 33. Social media dynamics of National Sports Federations | Facebook (USA) growth between Dec 2020 - Mar 2021.

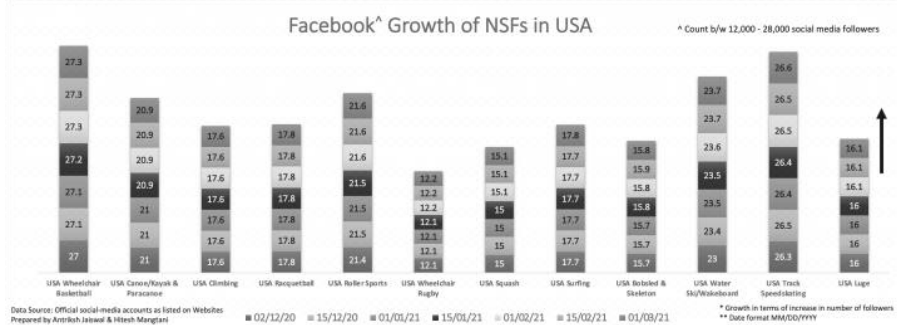

Figure 34. Social media dynamics of National Sports Federations $\mid$ Facebook (USA) growth between Dec 2020 - Mar 2021.

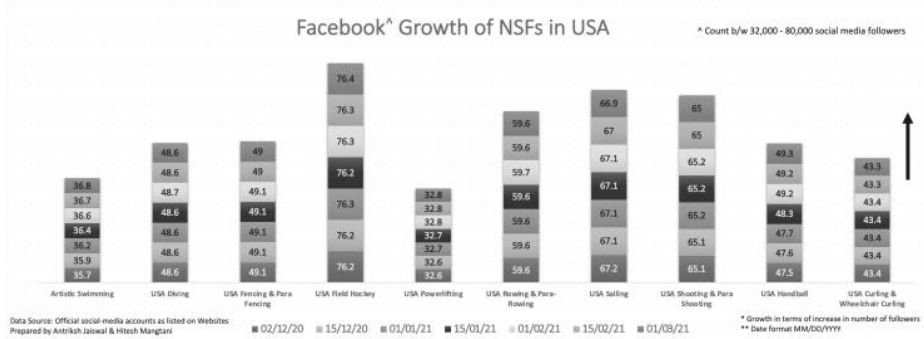

Figure 35. Social media dynamics of National Sports Federations $\mid$ Facebook (USA) growth between Dec 2020 - Mar 2021.

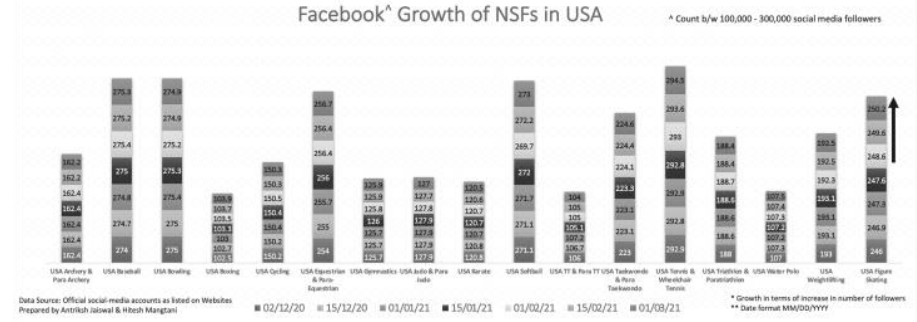

Figure 36. Social media dynamics of National Sports Federations | Facebook (USA) growth between Dec 2020 - Mar 2021.

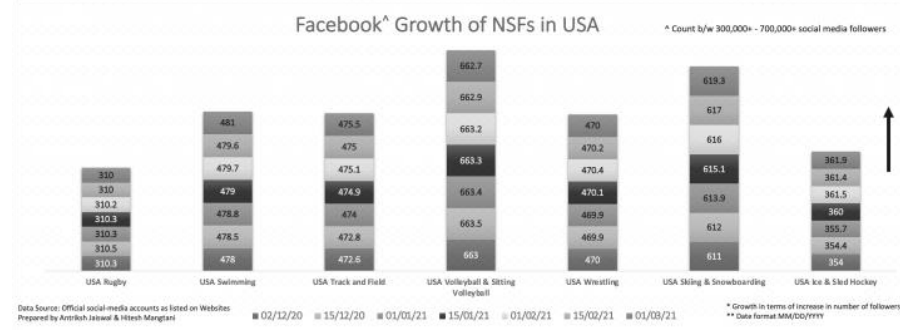

Figure 37. Social media dynamics of National Sports Federations | Facebook (USA) growth between Dec 2020 - Mar 2021.

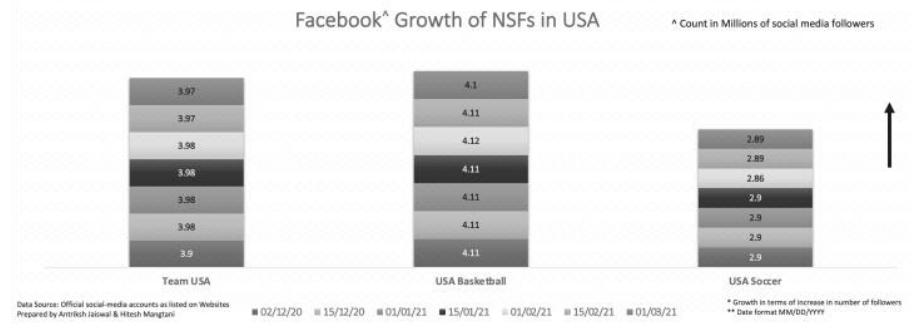

Figure 38. Social media dynamics of National Sports Federations | Facebook (USA) growth between Dec 2020 - Mar 2021.

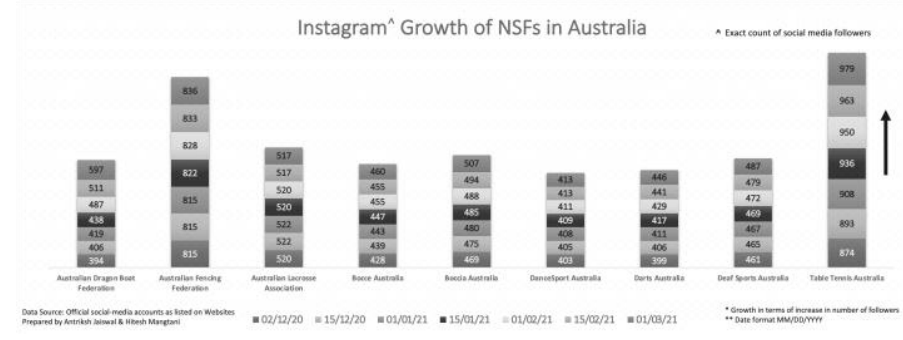

Figure 39. Social media dynamics of National Sports Federations | Instagram (Australia) growth between Dec 2020 - Mar 2021.

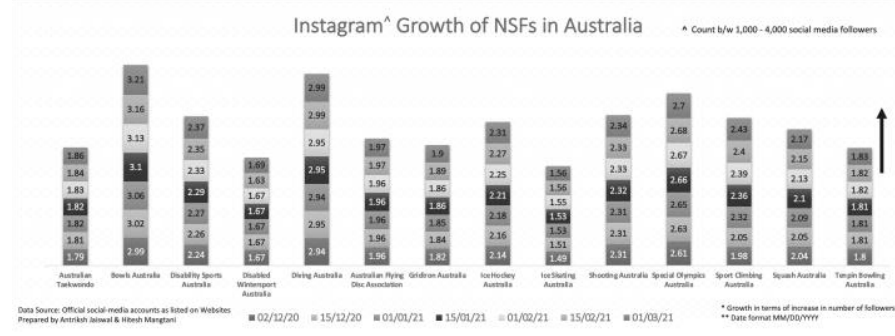

Figure 40. Social media dynamics of National Sports Federations | Instagram (Australia) growth between Dec 2020 - Mar 2021. 


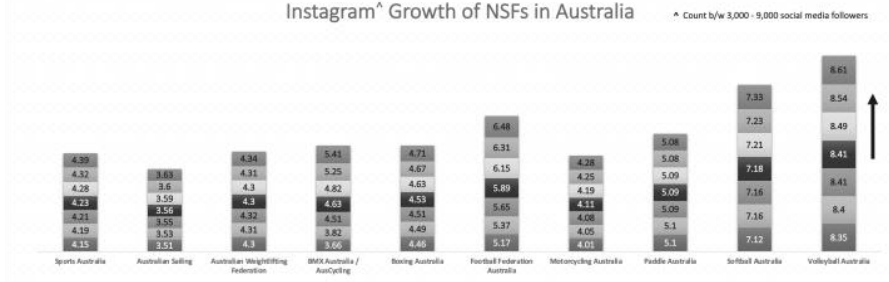

Figure 41. Social media dynamics of National Sports Federations | Instagram (Australia) growth between Dec 2020 - Mar 2021.

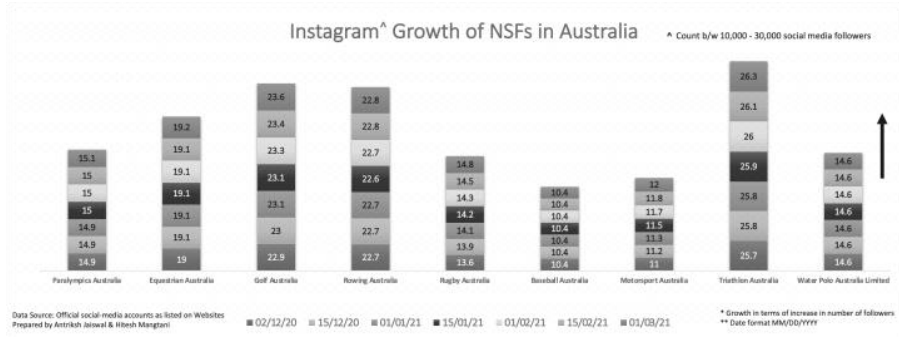

Figure 42. Social media dynamics of National Sports Federations | Instagram (Australia) growth between Dec 2020 - Mar 2021.

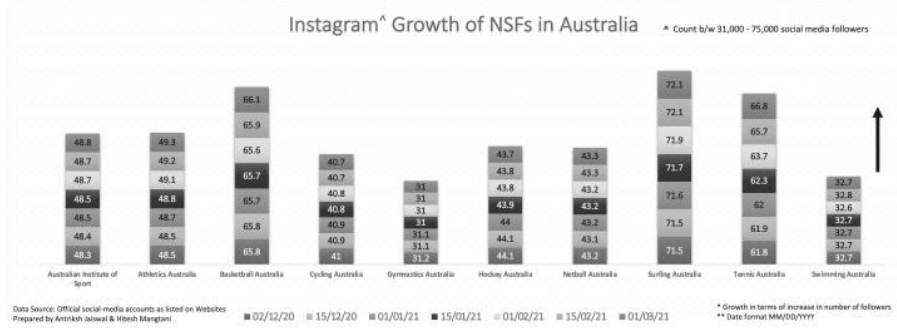

Figure 43. Social media dynamics of National Sports Federations | Instagram (Australia) growth between Dec 2020 - Mar 2021.

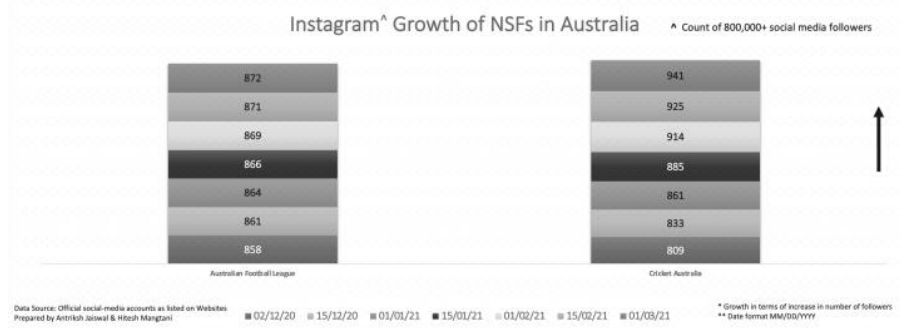

Figure 44. Social media dynamics of National Sports Federations $\mid$ Instagram (Australia) growth between Dec 2020 - Mar 2021.

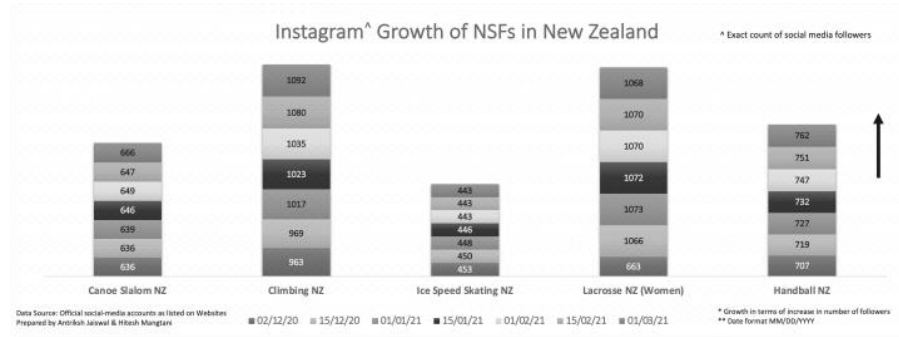

Figure 45. Social media dynamics of National Sports Federations $\mid$ Instagram (New Zealand) growth between Dec 2020 - Mar 2021.

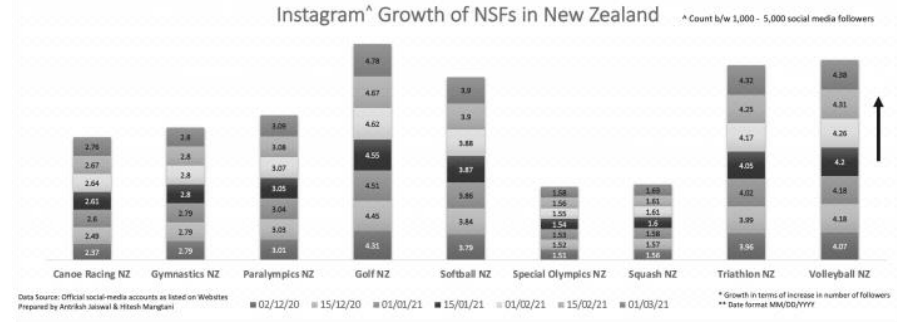

Figure 46. Social media dynamics of National Sports Federations | Instagram (New Zealand) growth between Dec 2020 - Mar 2021.

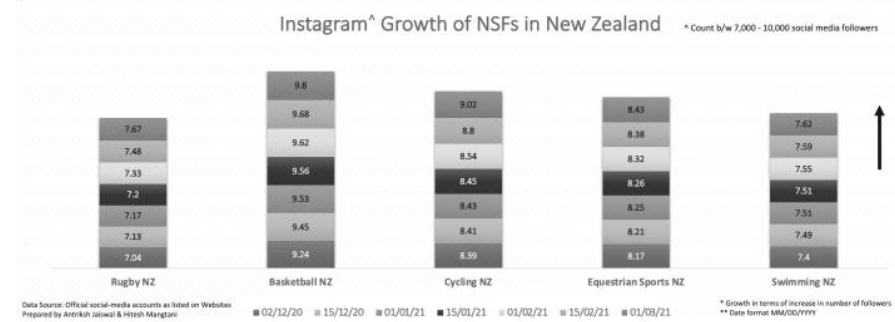

Figure 47. Social media dynamics of National Sports Federations | Instagram (New Zealand) growth between Dec 2020 - Mar 2021.

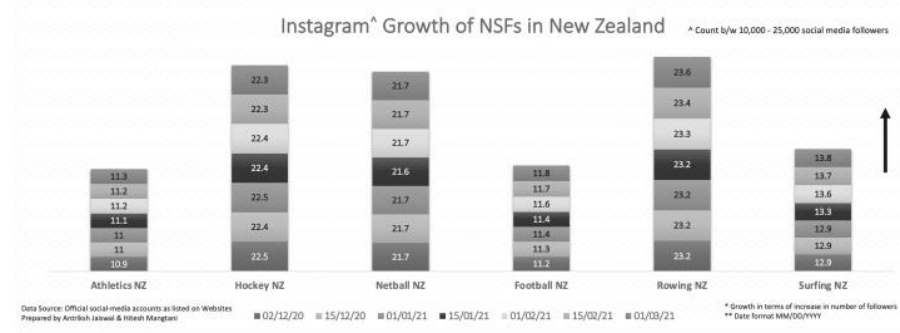

Figure 48. Social media dynamics of National Sports Federations | Instagram (New Zealand) growth between Dec 2020 - Mar 2021.

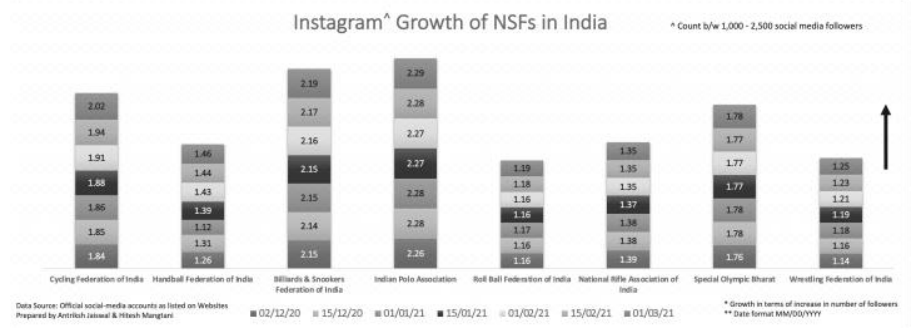

Figure 49. Social media dynamics of National Sports Federations | Instagram (India) growth between Dec 2020 - Mar 2021.

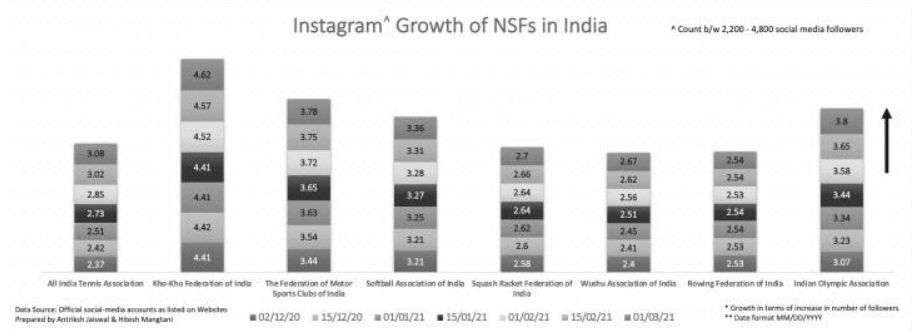

Figure 50. Social media dynamics of National Sports Federations $\mid$ Instagram (India) growth between Dec 2020 - Mar 2021. 


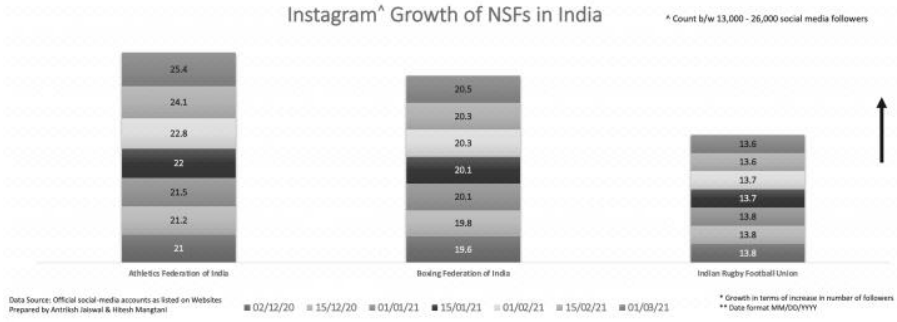

Figure 51. Social media dynamics of National Sports Federations | Instagram (India) growth between Dec 2020 - Mar 2021.

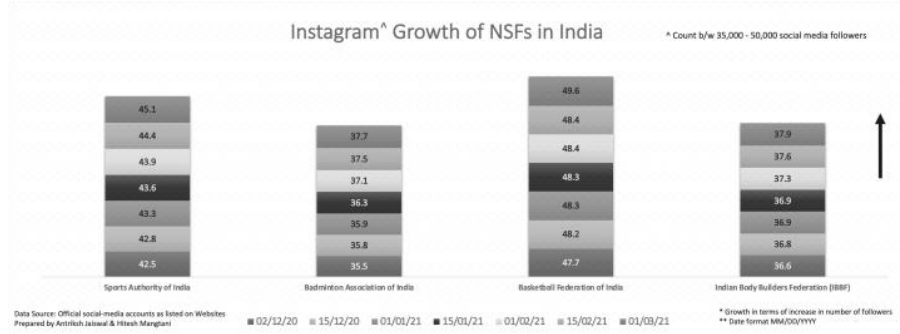

Figure 52. Social media dynamics of National Sports Federations | Instagram (India) growth between Dec 2020 - Mar 2021.

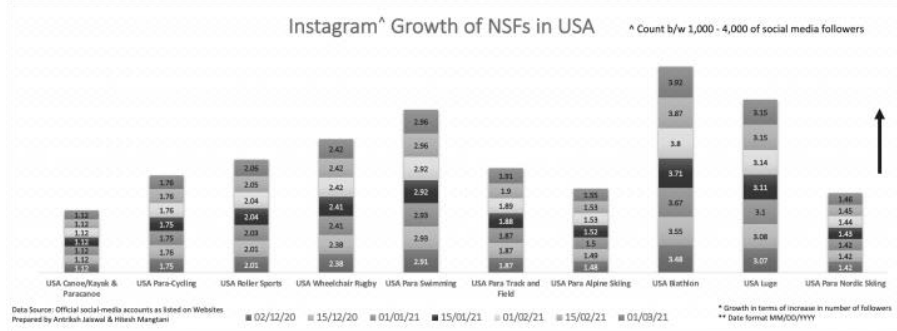

Figure 53. Social media dynamics of National Sports Federations $\mid$ Instagram (USA growth between Dec 2020 - Mar 2021.

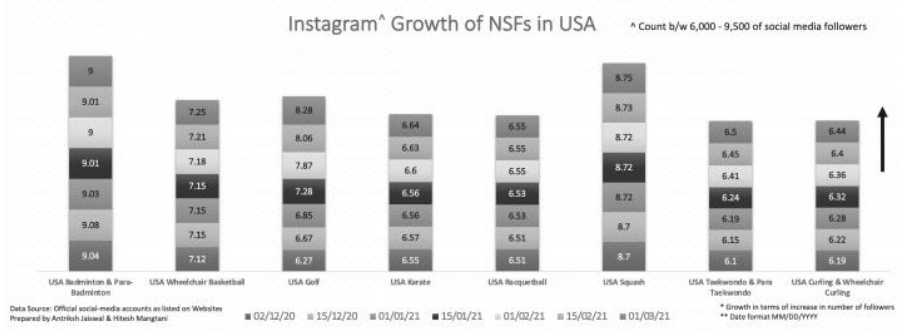

Figure 54. Social media dynamics of National Sports Federations | Instagram (USA) growth between Dec 2020 - Mar 2021.

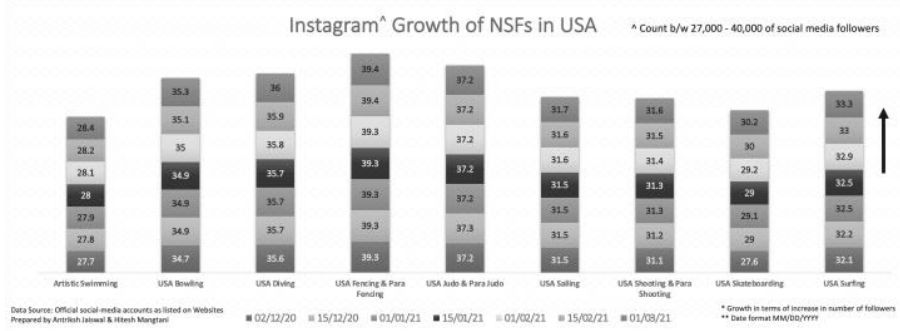

Figure 55. Social media dynamics of National Sports Federations | Instagram (USA growth between Dec 2020 - Mar 2021.

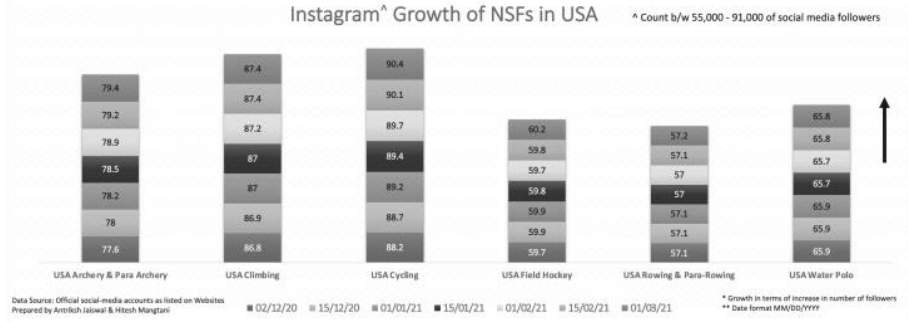

Figure 56. Social media dynamics of National Sports Federations | Instagram(USA) growth between Dec 2020 - Mar 2021.

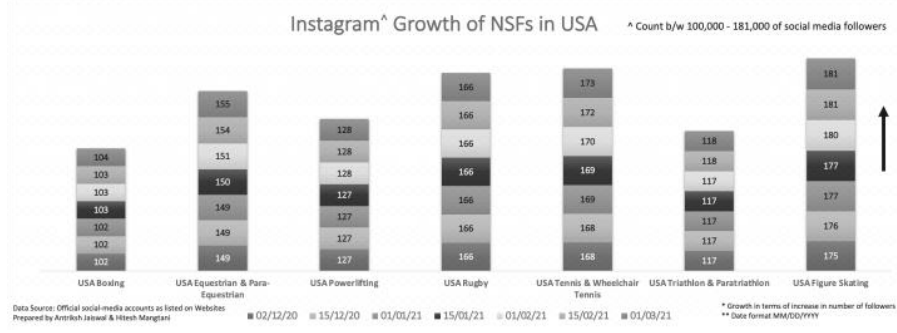

Figure 57. Social media dynamics of National Sports Federations | Instagram (USA) growth between Dec 2020 - Mar 2021.

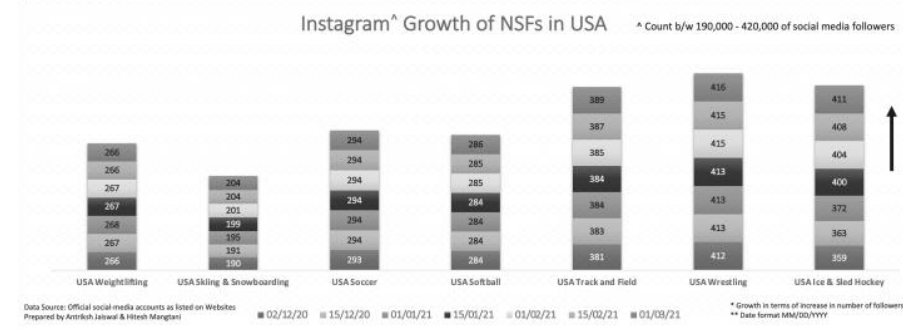

Figure 58. Social media dynamics of National Sports Federations | Instagram (USA) growth between Dec 2020 - Mar 2021.

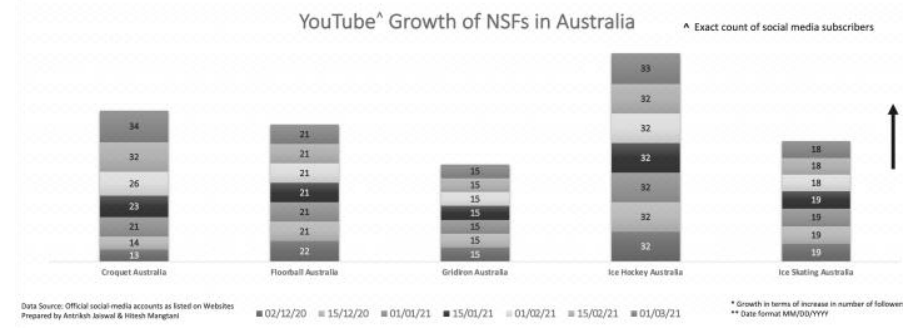

Figure 59. Social media dynamics of National Sports Federations | YouTube (Australia) growth between Dec 2020 - Mar 2021.

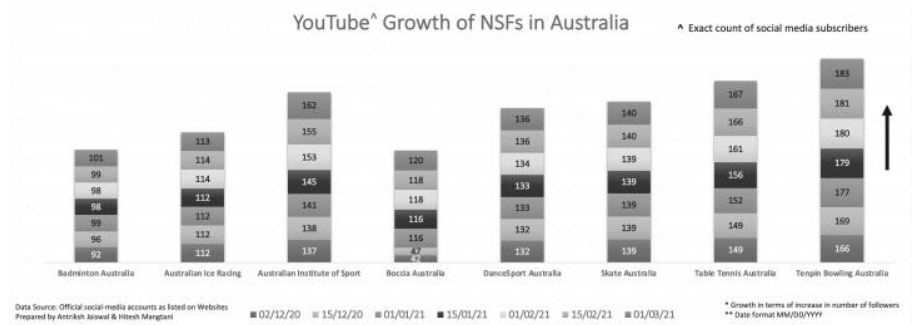

Figure 60. Social media dynamics of National Sports Federations | YouTube (Australia) growth between Dec 2020 - Mar 2021. 


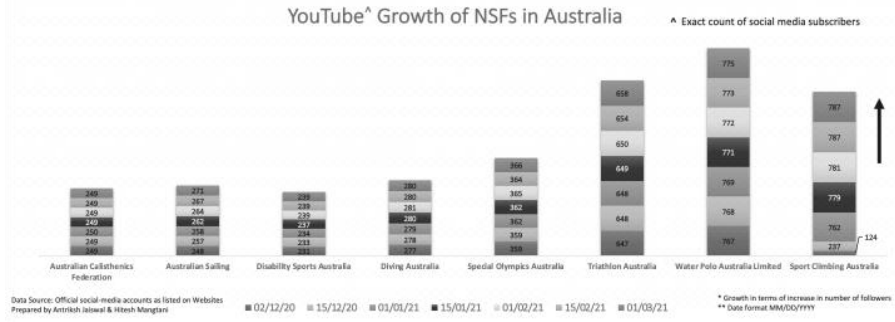

Figure 61. Social media dynamics of National Sports Federations $\mid$ YouTube (Australia) growth between Dec 2020 - Mar 2021.

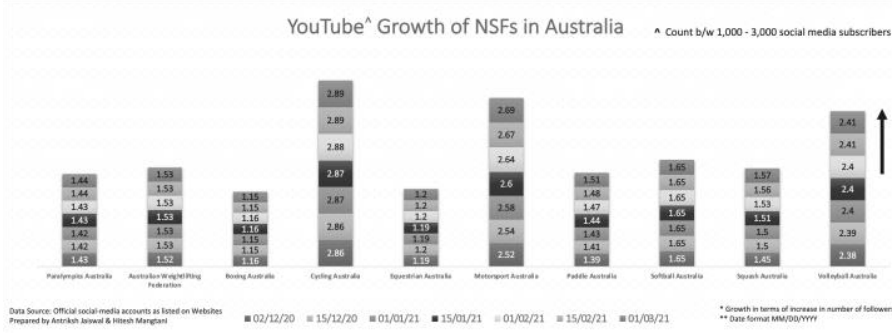

Figure 62. Social media dynamics of National Sports Federations $\mid$ YouTube (Australia) growth between Dec 2020 - Mar 2021.

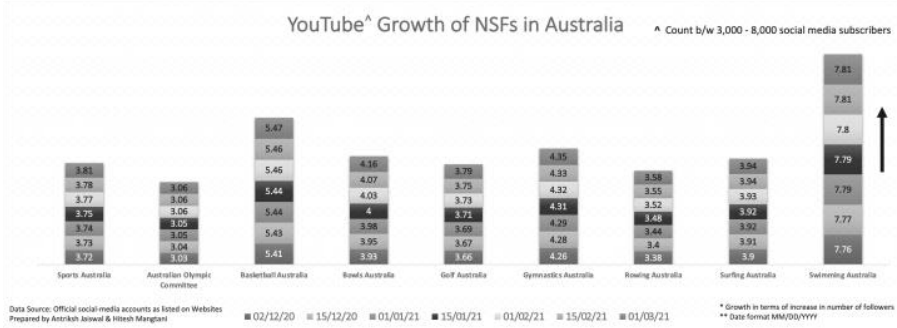

Figure 63. Social media dynamics of National Sports Federations | YouTube (Australia) growth between Dec 2020 - Mar 2021.

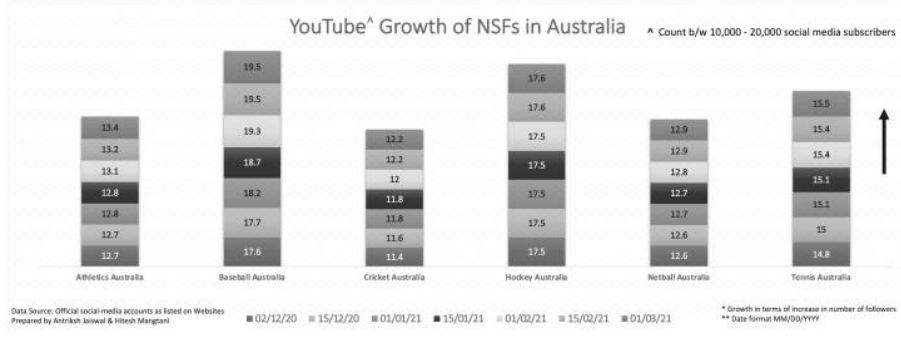

Figure 64. Social media dynamics of National Sports Federations | YouTube (Australia) growth between Dec 2020 - Mar 2021.

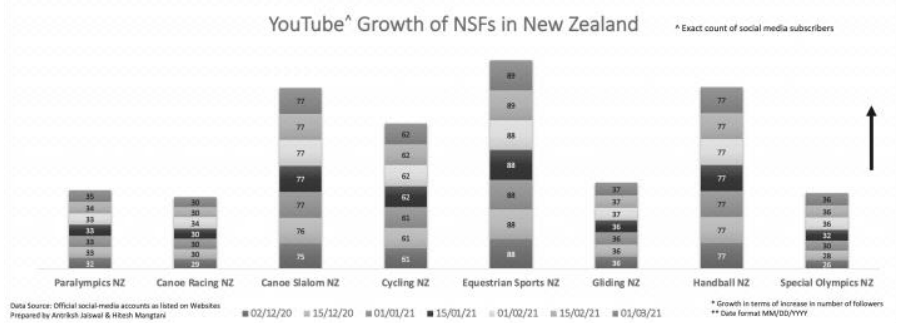

Figure 65. Social media dynamics of National Sports Federations | YouTube (New Zealand) growth between Dec 2020 - Mar 2021.

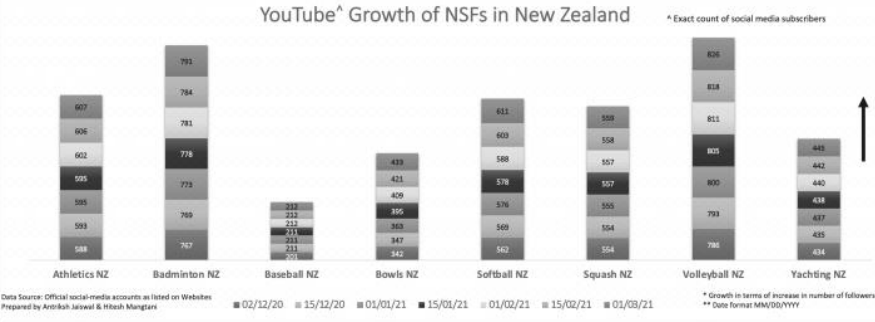

Figure 66. Social media dynamics of National Sports Federations | YouTube (New Zealand) growth between Dec 2020 - Mar 2021.

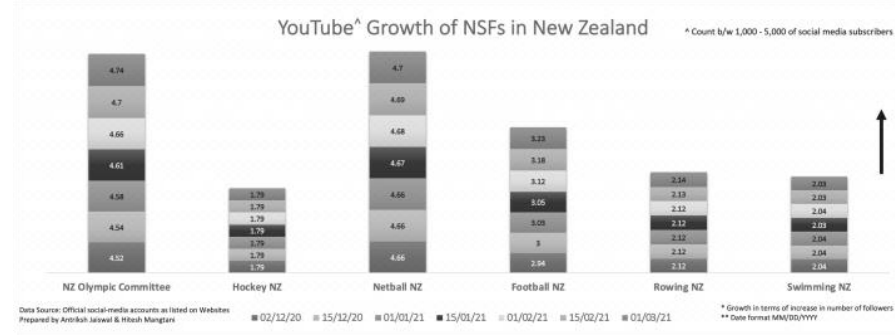

Figure 67. Social media dynamics of National Sports Federations $\mid$ YouTube (New Zealand) growth between Dec 2020 - Mar 2021.

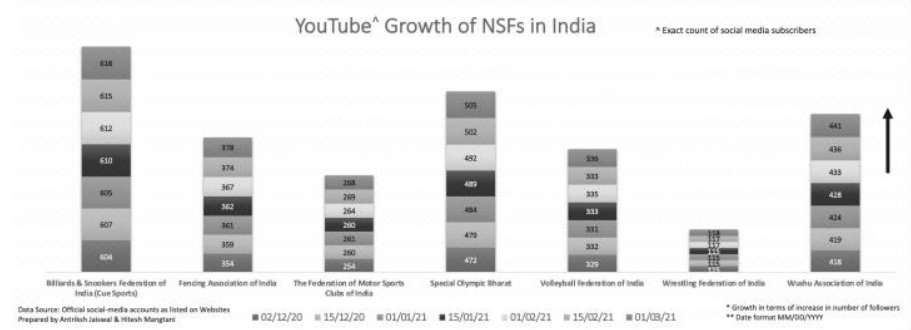

Figure 68. Social media dynamics of National Sports Federations |YouTube (India) growth between Dec 2020 - Mar 2021.

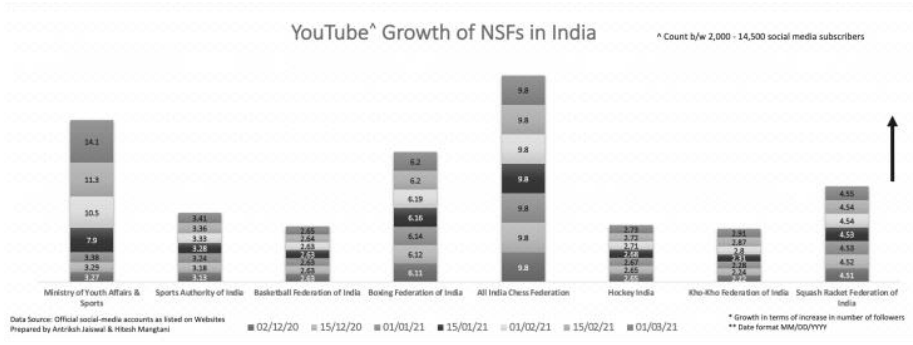

Figure 69. Social media dynamics of National Sports Federations | YouTube (India) growth between Dec 2020 - Mar 2021.

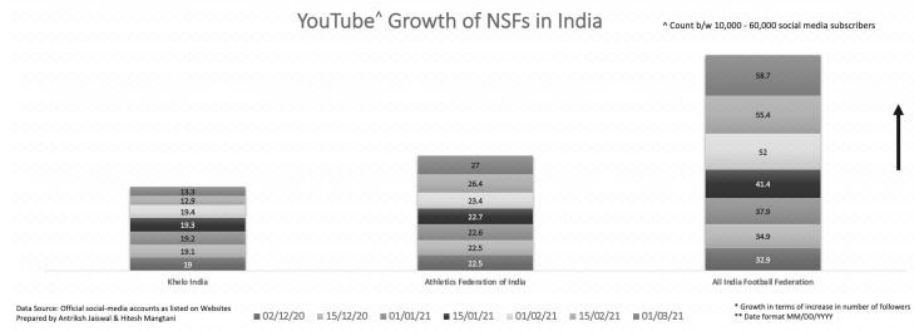

Figure 70. Social media dynamics of National Sports Federations | YouTube (India) growth between Dec 2020 - Mar 2021. 


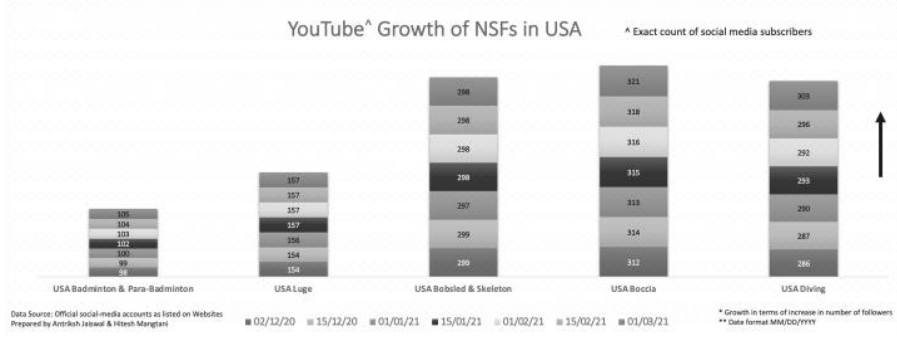

Figure 71. Social media dynamics of National Sports Federations $\mid$ YouTube (USA) growth between Dec 2020 - Mar 2021.

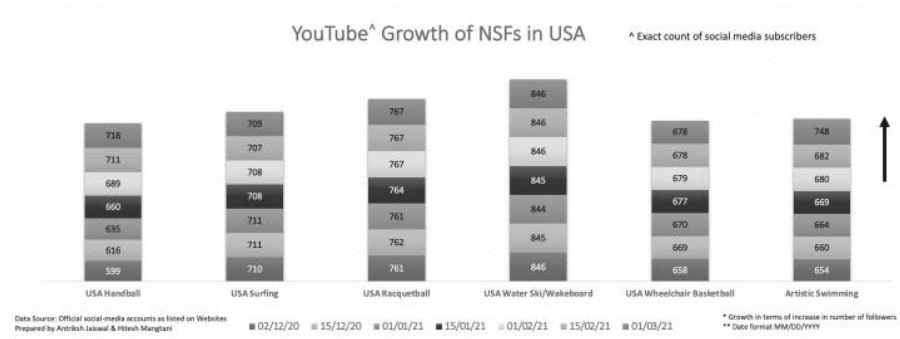

Figure 72. Social media dynamics of National Sports Federations $\mid$ YouTube (USA) growth between Dec 2020 - Mar 2021.

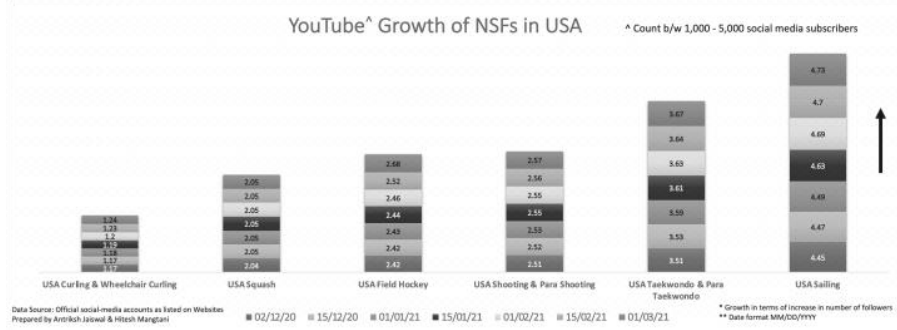

Figure 73. Social media dynamics of National Sports Federations $\mid$ YouTube (USA) growth between Dec 2020 - Mar 2021.

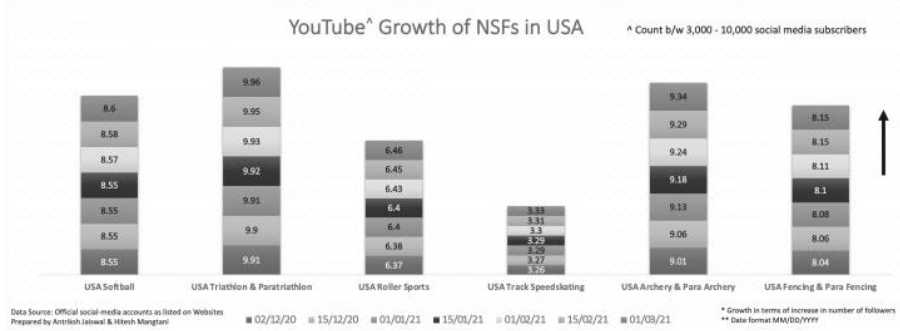

Figure 74. Social media dynamics of National Sports Federations $\mid$ YouTube (USA) growth between Dec 2020 - Mar 2021.

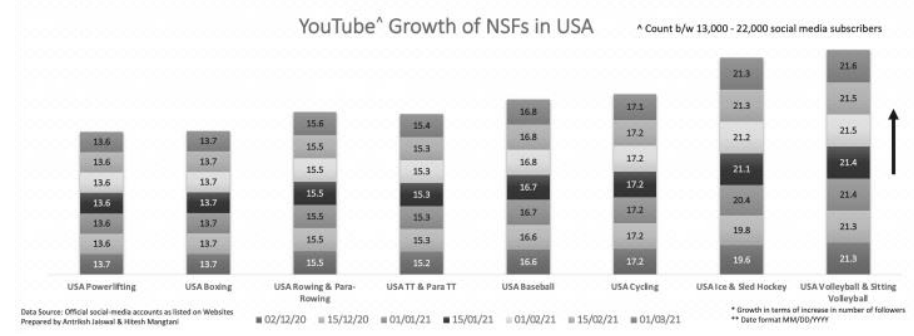

Figure 75. Social media dynamics of National Sports Federations | YouTube (USA) growth between Dec 2020 - Mar 2021.

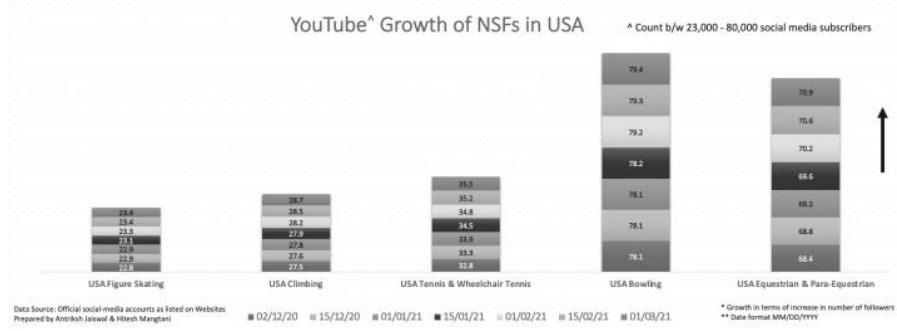

Figure 76. Social media dynamics of National Sports Federations | YouTube (USA) growth between Dec 2020 - Mar 2021.

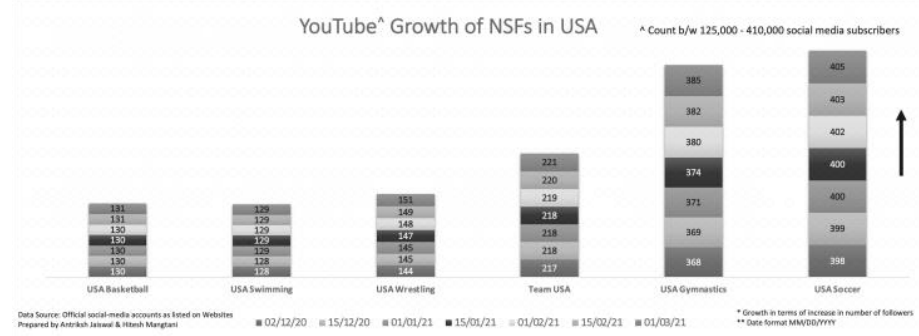

Figure 77. Social media dynamics of National Sports Federations $\mid$ YouTube (USA growth between Dec 2020 - Mar 2021. 


\section{CONCLUSION}

Governing Bodies of Sports or the National Sports Federations (NSFs) in this era have been in the limelight all of a sudden, specifically if we consider the Indian market, where the Business of Sports aspect has got so much popularity and that a dedicated profession has been brought into the context, i.e., Sports Management be it a Bachelor Degree Program or a Post-Graduate Program. The line of reasoning we have been trying to make is that the NSFs or Governing Bodies need to act in a professional manner (specifically in the Indian sub-continent), and use social media platforms for the right context, the right reasons and most importantly for the development of sports, instead of just trying to create a political image for themselves.

Legendary Indian shuttler Prakash Padukone shared his valuable perspective ${ }^{(50)}$ a while ago that, being a sports administrator or an athlete or maybe a sports manager in the ecosystem nowadays isn't just a part-time job, it has to be a full-time job be it the physios, trainers, or management professionals. Social media has changed the way how fans consume diversified sports content. The most striking feature is that the sports fans are the most active on social media platforms voicing their opinions and suggesting changes. Never in the history of sports, fan engagement has taken centre stage in 2019. Today, the use of social media is being considered as one of the Key Performance Indicators (KPIs) for the overall measurement or evaluation of the success or failure of the respective organization(s) (specific to NSFs and governing bodies of sports).

With the introduction of technology-based measurement, or evaluation systems and analytical/statistical tools in the sports ecosystem, claiming to be running a successful campaign or fantasizing to be the leading sports administrators isn't going to work because the people of different age groups, now have the capacity, ability and the techniques in their hands to monitor, extract and formulate the precise parameters. These parameters are the ones being used for the overall judgement and final evaluation of the respective campaign, development scheme ${ }^{(29)}$ or management program, directly linked to the revenue generation strategies, sponsorship commitments and future objectives.

Based on the data of this research for all National Sports Federations (NSFs) of all four countries namely Australia ${ }^{(6)}$, New Zealand ${ }^{(7)}$, India ${ }^{(8)}$, USA ${ }^{(9)}$ and facts collected from multiple sources, it is our understanding that social media platforms in this highly

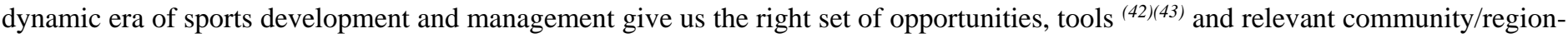
specific louds and softs to attract tactically aligned sponsorship or partnerships opportunities ${ }^{(35)(44)}$, to further our efforts in terms of becoming a self-sustainable platform vis-à-vis revenue generation or maintaining financial stability.

\section{REFERENCES}

[1] Kotler, P., Keller, K. L. (2016). Marketing Management. India: Pearson.

[2] IOC (2020). International Sports Federations with Olympic Recognition. Available on: https://www.olympic.org/ioc-governance-international-sports-federations

[3] IPC (2020). International Sport Federations | International Paralympic Committee (IPC). Available on: https://www.paralympic.org/ipc/federations

[4] United Nations Statistical Division (UNSD), (2020). The Sustainable Development Goals Report 2020. Available on: https://unstats.un.org/sdgs/report/2020/TheSustainable-Development-Goals-Report-2020.pdf.

[5] Mangtani, H., 2020. Would you call yourself 'a fan' or 'an antagonist'?, Available at: https://www.linkedin.com/today/author/hiteshmangtani.

[6] Sport Australia, 2020. sportaus.gov.au. Available on: https://www.sportaus.gov.au/australian_sports_directory.

[7] MYAS (2020). List of Recognized NSFs 2020-2021. Available on: https://yas.nic.in/sports/list-of-recognised-national-sports-federations-for-the-year-20202021? page $=1$.

[8] Sport New Zealand, (2020). sportnz.org.nz. Available on: https://sportnz.org.nz/find-a-sport-or-recreation-activity/.

[9] Team USA, (2020). teamusa.org. Available on: https://www.teamusa.org/.

[10] Mangtani, H. \& Jaiswal, A., 2020. A Blessing Or Blight: How Can COVID-19 Help In Effective Understanding Of Grassroots Development In Sports? Available at: https://www.linkedin.com/pulse/blessing-blight-how-can-covid-19-help-effective-sports-mangtani?trk=portfolio_article-card_title.

[11] Burson Cohn \& Wolfe 2019 ranking of International Federations social media activities shows a need for increased focus on community building - BCW Sport Burson Cohn \& Wolfe (BCW). (2020). Available on: https://bcw-sport.com/press/burson-cohn-wolfe-2019-ranking-of-international-federations-social-mediaactivities-shows-a-need-for-increased-focus-on-community-building/.

[12] Cowan, J., Birch, D. \& Leed, O., 2020. Global Sports Innovation Center (GSIC) Webinar - Embracing The Multisport Through Technology And Innovation.

[13] Donovan, J., 2021. How Social Media's Obsession With Scale Supercharged Disinformation. Available at: https://hbr.org/2021/01/how-social-medias-obsessionwith-scale-supercharged-disinformation.

[14] Eisenstat, Y., 2021. How To Hold Social Media Accountable For Undermining Democracy? hbr.org. Available at: <https://hbrorg.cdn.ampproject.org/c/s/hbr.org/amp/2021/01/how-to-hold-social-media-accountable-for-undermining-democracy>.

[15] Gilbert, B., 2019. Facebook Is Changing Its Logo To Make Sure Users Know It Owns Instagram And WhatsApp. Inc.com. Available at: <https://www.inc.com/business-insider/facebook-new-logo-instagram-whatsapp-parent-company.html>.

[16] Moneycontrol (2020). Timeline Of Facebook's Major Acquisitions Since Inception. Available at: <https://www.moneycontrol.com/news/photos/business/stocks/sharekhan-picks-these-12-stocks-for-double-digit-returns-in-the-long-term-6334251.html>.

[17] United Nations (2021).Take Action For The Sustainable Development Goals (SDGs). Available at: https://www.un.org/sustainabledevelopment/sustainabledevelopment-goals/. 
[18] Olympic.org. 2017. International Olympic Committee (IOC) and United Nations (UN) - Tapping The Full Potential Of Sport. Available at: https://www.olympic.org/cooperation-with-the-un.

[19] TED Conferences, 2020. Dear Facebook, this Is How You're Breaking Democracy. Available at: https://www.ted.com/talks/yael_eisenstat_dear_facebook_this_is_how_you_re_breaking_democracy?language=en\#t-112058.

[20] Netball New Zealand. (2021). Available on: https://www.netballnz.co.nz/

[21] Social Blade LLC. (2021). Available on: https://socialblade.com/youtube/channel/UCsMwUgtc13sVboZOEbPiCLw

[22] Grohmann, K. (2021). Olympics-Surfing and breakdancing among four sports to win Paris 2024 spot. Available on: https://in.reuters.com/article/olympics-iocint/olympics-surfing-and-breakdancing-among-four-sports-to-win-paris-2024-spot-idUSKBN28H2BL

[23] CNBC International TV. (2017). How do you put a financial value on sports sponsorship? Available at: https://www.youtube.com/watch?v=hGB7AN326Zc

[24] CNBC, (2019). Why NBA Players Out Earn Other US Athletes. Available at: https://www.youtube.com/watch?v=u7uwCx91gpE

[25] Hero MotoCorp. (2020). Get. Set. \#GOBOOM. Available at: https://www.youtube.com/watch?v=IWcyj55qzuc

[26] IOC Media. (2020). IOC Marketing And Broadcasting - Olympic Marketing Fact File. Available at: https://olympics.com/ioc/documents/international-olympiccommittee/ioc-marketing-and-broadcasting.

[27] IOC Media, (2016). IOC Marketing and Broadcasting - Global Broadcast and Audience Report - Olympic Games Rio 2016. Available at: https://olympics.com/ioc/documents/international-olympic-committee/ioc-marketing-and-broadcasting.

[28] Stats NZ, (2020). New Zealand's population passes 5 million. Available at: https://www.stats.govt.nz/news/new-zealands-population-passes-5-million.

[29] Hitesh Mangtani (2021); Coaching and Scouting: A managerial framework for Sports Development; International Journal of Scientific and Research Publications (IJSRP) 11(5) (ISSN: 2250-3153), DOI: http://dx.doi.org/10.29322/IJSRP.11.05.2021.p11321

[30] BARC India, (2021). The Year After Two Thousand \& Nineteen. BARC India Yearbook. Mumbai (India): Broadcast Audience Research Council (BARC), India. Available at: https://www.barcindia.co.in/announcement/barc-india-launches-the-third-edition-of-its-yearbook.pdf.

[31] Wimbledon, (2019). Novak Djokovic vs Roger Federer | Wimbledon 2019. Available at: https://www.youtube.com/watch?v=TUikJi0Qhhw

[32] Olympics, (2019). A Badminton Shot faster than $500 \mathrm{~km} / \mathrm{h}$ ? (ft. Carolina Marin) | Is It Possible? Available at: https://www.youtube.com/watch? $\mathrm{v}=\mathrm{ksgbaKSwe} 5 \mathrm{~A}$.

[33] The World Bank (2019). Total Population - Australia Data. Available at: https://data.worldbank.org/indicator/SP.POP.TOTL?locations=AU

[34] The World Bank (2019). Total Population - United States Data. Available at: https://data.worldbank.org/indicator/SP.POP.TOTL?locations=US

[35] MIT Sloan Sports Analytics Conference, (2019). SSAC19: How to Advertise Effectively on Facebook and Instagram. Available at: https://www.youtube.com/watch?v=I_xRZ913WCw\&list=PLhbPeSFiFnAbTHGwepXMqLhD2RwTex0jQ\&index=6

[36] Ingle, S., (2021). Sports bodies to boycott social media for bank holiday weekend over abuse. Available at: https://www.theguardian.com/sport/2021/apr/29/major-sports-bodies-84-hour-social-media-boycott-over-online-abuse-facebook-twitter.

[37] Reuters, (2021). Sport unites for social media boycott against online abuse. Available at: https://www.reuters.com/article/uk-sport-racism-idUKKBN2CH2JI.

[38] Brewis, H., 2020. Take the knee: Thousands of Brits kneel for Black Lives Matter tribute. Available at: https://www.standard.co.uk/news/uk/take-knee-blacklives-matter-uk-george-floyd-protests-a4465531.html.

[39] Influencer Marketing Hub, (2020). Influencer Marketing Benchmark Report: 2020 by Influencer Marketing Hub in association with Creator IQ. Available at: https://influencermarketinghub.com/influencer-marketing-benchmark-report-2020/.

[40] Influencer Marketing Hub, (2021). Influencer Marketing Benchmark Report: 2021 by Influencer Marketing Hub in association with Upfluence. Available at: https://influencermarketinghub.com/influencer-marketing-benchmark-report-2021/.

[41] Business Insider, (2021). Influencer Marketing in the Age of COVID-19 - How Brands and Creators Are Adapting to a 'New Normal'. Business Insider Intelligence. Available at: https://www.businessinsider.com/influencer-marketing-report?IR=T.

[42] Mohammad Kazemi, Reza. (2015). Sports Marketing \& social Media. 10.4018/978-1-4666-8353-2.ch0020.

[43] Filo, Kevin \& Lock, Daniel \& Karg, Adam. (2015). Sport and social media research: A review. Sport Management Review. 18. 10.1016/j.smr.2014.11.001.

[44] MIT Sloan Sports Analytics Conference, (2019). SSAC19: Social Media in MLB: A Data-Driven Approach to Optimizing Strategy. Available at: https://www.youtube.com/watch?v=dp-1Fo93E0s\&list=PLhbPeSFiFnAbTHGwepXMqLhD2RwTex0jQ\&index=10

[45] McCoy, E., (2019). HOW OUR BRAINS ARE HARDWIRED FOR VISUAL CONTENT. Killer Visual Strategies | A Material Company, Available at: https://killervisualstrategies.com/blog/how-our-brains-are-hardwired-for-visual-content.html.

[46] Firth, J., Torous, J., Stubbs, B., Firth, J. A., Steiner, G. Z., Smith, L., Alvarez-Jimenez, M., Gleeson, J., Vancampfort, D., Armitage, C. J., \& Sarris, J. (2019). The "online brain": how the Internet may be changing our cognition. World psychiatry : official journal of the World Psychiatric Association (WPA), 18(2), 119-129. https://doi.org/10.1002/wps.20617

[47] Association of National Olympic Committees (ANOC), (2021). IOA, COM, JOC, SAOC and CNOM experienced the largest follower growth across Facebook, Twitter, Instagram and Youtube in April. (Twitter Post). Available on: https://twitter.com/ANOC_Olympic/status/1391669556830146561

[48] International Olympic Committee, (2020). Olympic Charter in effect from $17^{\text {th }}$ July 2020. Lausanne: International Olympic Committee, Rule 7, "Rights over the Olympic Games and Olympic Properties." Available at: https://stillmed.olympic.org/media/Document\%20Library/OlympicOrg/General/EN-Olympic-Charter.pdf.

[49] International Paralympic Committee, (2016). The Paralympic symbol - What does the Agitos mean?.Available at: https://www.paralympic.org/video/paralympicsymbol-what-does-agitos-mean.

[50] Scroll.in, (2018). Scroll Conversations | Prakash Padukone.Available at: <https://www.youtube.com/watch?v=cPGgkh51YMk.

\section{AUTHORS}

First Author - Hitesh Mangtani, Independent Researcher (Sports), MBA-Sports Management, hiteshmangtani04@ gmail.com.

Second Author - Antriksh Jaiswal, Former-Senior Digital Strategist - ITW Consulting Pvt. Ltd., antriksh.jaiswal01@ gmail.com.

Correspondence Author - Hitesh Mangtani, hiteshmangtani04@gmail.com 